\title{
Protocols for isolating and characterizing polysaccharides from plant cell walls: a case study using rhamnogalacturonan-II
}

\author{
William J. Barnes', Sabina Koj ${ }^{1}$, Ian M. Black', Stephanie A. Archer-Hartmann ${ }^{1}$, Parastoo Azadi ${ }^{1}$, \\ Breeanna R. Urbanowicz ${ }^{1,2^{*}} \mathbb{D}$, Maria J. Peña ${ }^{1 *}$ and Malcolm A. O'Neill ${ }^{1 *}$
}

\begin{abstract}
Background: In plants, a large diversity of polysaccharides comprise the cell wall. Each major type of plant cell wall polysaccharide, including cellulose, hemicellulose, and pectin, has distinct structures and functions that contribute to wall mechanics and influence plant morphogenesis. In recent years, pectin valorization has attracted much attention due to its expanding roles in biomass deconstruction, food and material science, and environmental remediation. However, pectin utilization has been limited by our incomplete knowledge of its structure. Herein, we present a workflow of principles relevant for the characterization of polysaccharide primary structure using nature's most complex polysaccharide, rhamnogalacturonan-II (RG-II), as a model.
\end{abstract}

Results: We outline how to isolate RG-II from celery and duckweed cell walls and from red wine using chemical or enzymatic treatments coupled with size-exclusion chromatography. From there, we applied mass spectrometry (MS)based techniques to determine the glycosyl residue and linkage compositions of the intact RG-II and derived oligosaccharides including special considerations for labile monosaccharides. In doing so, we demonstrated that in the duckweed Wolffiella repanda the arabinopyranosyl (Arap) residue of side chain B is substituted at O-2 with rhamnose. We used electrospray-MS techniques to identify non-glycosyl modifications including methyl-ethers, methyl-esters, and acetyl-esters on RG-II-derived oligosaccharides. We then showed the utility of proton nuclear magnetic resonance spectroscopy ('H-NMR) to investigate the structure of intact RG-II and to complement the RG-II dimerization studies performed using size-exclusion chromatography.

Conclusions: The complexity of pectic polysaccharide structures has hampered efforts aimed at their valorization. In this work, we used RG-II as a model to demonstrate the steps necessary to isolate and characterize polysaccharides using chromatographic, MS, and NMR techniques. The principles can be applied to the characterization of other saccharide structures and will help inform researchers on how saccharide structure relates to functional properties in the future.

Keywords: Rhamnogalacturonan-II (RG-II), Pectin, Plant cell wall, Borate diester, SEC-MALS, NMR spectroscopy

*Correspondence: breeanna@uga.edu; pena@ccrc.uga.edu; mao@ccrc.uga. edu

${ }^{1}$ Complex Carbohydrate Research Center, The University of Georgia, 315 Riverbend Road, Athens, GA 30602, USA

Full list of author information is available at the end of the article

\section{Background}

Plant cell walls are the major component of plant biomass and represent a largely under-utilized renewable resource for the generation of materials, fuels, and highvalue chemicals. These walls are largely composed of cellulose, hemicelluloses, and pectins, as well as wall-bound proteins and lignin. These components dynamically 
interact at the molecular level to control the structure and mechanical characteristics of cell walls, which in turn are intimately involved in determining plant morphology and function from the cellular to tissue scale. Moreover, cell wall composition is directly related to how plants develop, reproduce, and thus provide food and materials. To date, considerable effort has been dedicated to dissecting the functional contributions of individual wall components through genetic and biomechanical studies of plant cell and organ growth. For example, cellulose exists in a microfibril form composed of coalesced glucan chains that provide a rigid, 'load-bearing' scaffold with high tensile strength and the ability to constrain the growth of plant cells [1]. The fibrils are believed to noncovalently interact with hemicelluloses to control wall biomechanics and the organization of the cellulose during wall expansion [2-4]. Early models of the cell wall predicted that the cellulose-hemicellulose scaffold was embedded in a pectin matrix that itself had only a limited effect on wall properties. However, there is now an increasing awareness that pectins are a dynamic type of polysaccharide that associate with cellulose and hemicelluloses to determine wall charge, porosity, rigidity and hydration [5-8].

Pectins are of particular importance for cell expansion $[9,10]$, fruit ripening and plant organ abscission [11], pollen dehiscence $[12,13]$, seed hydration $[14,15]$, and cell-cell adhesion [16-20]. Pectic structures vary considerably depending on plant taxonomy, tissue, and developmental stage. Pectins and pectin oligosaccharides act as developmental cues and elicitors in pathogen defense. Traditionally, pectins are used commercially as thickeners, stabilizers, and gelling agents [21]. Pectins also serve as a prominent component of dietary fiber for humans. More recently, pectins have become a target of efforts to produce plants with increased yield and reduced biomass recalcitrance [9, 22-24]. Pectins have also been shown to have the potential for the creation of edible foodpackaging [25], the treatment of gastrointestinal disorders [26], and the removal of metals and contaminants in wastewater [27]. Thus, pectins in general are a family of polysaccharides that are unique in form and function.
Nevertheless, their valorization has been limited by the challenges involved in determining their primary structures and relating how these structures contribute to their functional properties.

Pectins are classified into several general typeshomogalacturonan (HG), rhamnogalacturonan-I (RGI), rhamnogalacturonan-II (RG-II), apiogalacturonan (AGA), xylogalacturonan (XGA), and pectin-containing arabinogalactan protein (APAP1) - based on the structures of their backbone and substituents [28, 29]. HG, RG-II, AGA, and XGA have a backbone of 1,4-linked $\alpha$-D-galacturonic acid (GalA) residues, which may be substituted with glycosyl and non-glycosyl substituents to form distinct pectin 'domains' (Fig. 1a) [29, 30]. For example, the structural diversity of HG results from the methyl-esterification of the carboxyl groups $(C-6)$ of GalA and by $O$-acetylation of GalA at $O-2$ or $O-3$ [31]. In contrast, RG-I has a backbone of the repeating disaccharide 4$)-\alpha-D-G a l A-(1,2)-\alpha-L-R h a-(1$ that is substituted at $O-4$ of the rhamnose (Rha) by galactose (Gal) and arabinofuranose (Araf)-containing side chains [29]. The backbone may also be $O$-acetylated.

RG-II (Fig. 1b) is the most structurally elaborate polysaccharide characterized to date and provides a compelling example of the byzantine nature of plant polysaccharides [32]. RG-II contains 11 different monosaccharides that are connected by at least 20 distinct glycosidic linkages (Fig. 1b, c). Further structural complexity is introduced by methyl-esterification, methyl-etherification, and $O$-acetylation of specific glycosyl residues [33]. Six side chains (termed A-F) branch off of the HG backbone, which has a degree of polymerization of at least eight GalA residues (Fig. 1b). Side chains A and B are oligosaccharides whereas $\mathrm{C}$ and $\mathrm{D}$ are disaccharides. $\mathrm{E}$ and $\mathrm{F}$ comprise a single $\alpha$ - $\mathrm{L}$-Araf $\mathrm{f}$ residue linked to $\mathrm{O}-3$ of a backbone GalA or a backbone GalA that is also substituted at $\mathrm{O}-2$ with side chain A [34]. The structures of side chains $C$ and $D$ are conserved, whereas side chains $A$ and $B$ exhibit some structural diversity throughout vascular plants. Side chains A and B are linked to $O-2$ of a backbone GalA via a $\beta$-D-apiosyl (Api) residue, but only the Api of side chain A has been shown to participate in

\footnotetext{
(See figure on next page.)

Fig. 1 The isolation and glycosyl sequence of rhamnogalacturonan-II. a Schematic representation of the extraction of non-proteinaceous pectic domains including homogalacturonan (HG), rhamnogalacturonan-I (RG-I), and rhamnogalacturonan-II (RG-II) from alcohol insoluble residue (AIR). Covalently linked multi-domain pectin molecules can be released by oxalate extraction if necessary (duckweed preparation). AIR or isolated multi-domain pectin molecules are then treated with endopolygalacturonase (EPG) to hydrolyze the HG backbone to separate the pectic domains. Purple arrowheads represent sites of EPG cleavage on the HG backbone. b The glycosyl sequence of the rhamnogalacturonan-II (RG-II) monomer. The apiosyl residue involved in the formation of the borate diester cross-linked dimer is shown. Also shown are the sites of structural diversity in RG-II glycoforms isolated from different plants with or without Araf and Rha extensions of side chain B and L-Fuc instead of L-Gal in side chain A. The RG-II structure depicted, which includes all of the known non-carbohydrate substituents, has a nominal molecular mass of 5094 Da. c The RG-II-relevant symbols from the symbol nomenclature for glycans (www.ncbi.nlm.nih.gov/glycans/snfg.html) with minor modifications so they are accessible to people with color blindness
} 


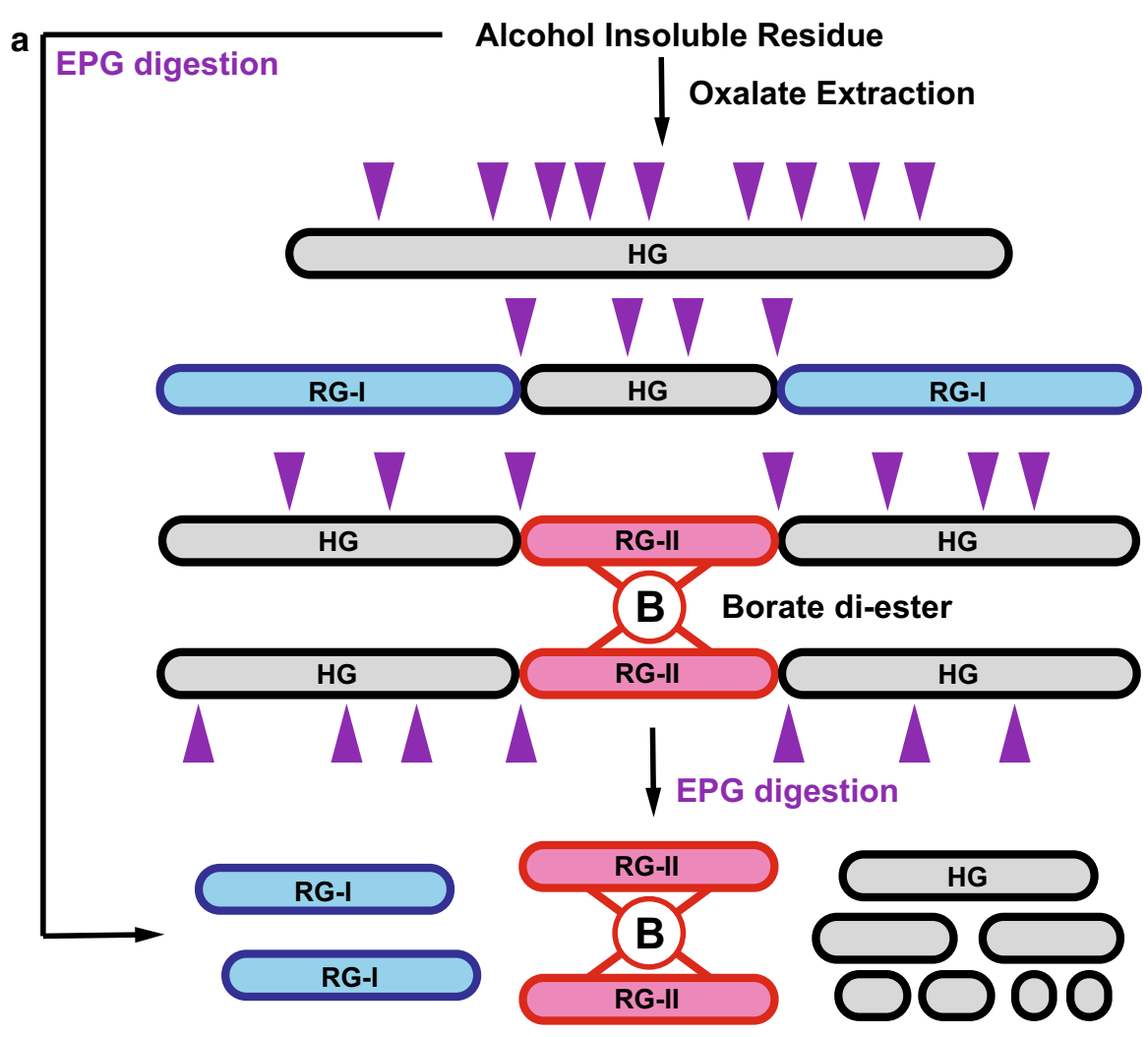

b RG-II Monomer

Glycoforms: L-Fuc or L-Gal

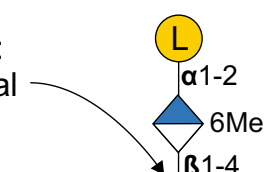

\section{Chain B}

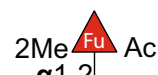

a1-2
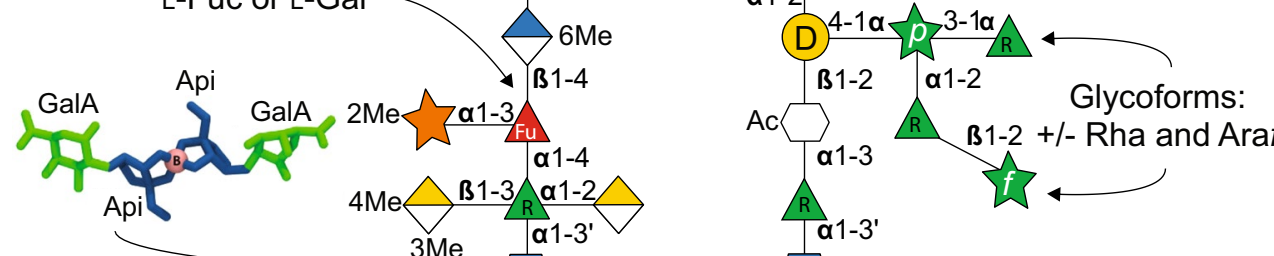

Site of crosslink

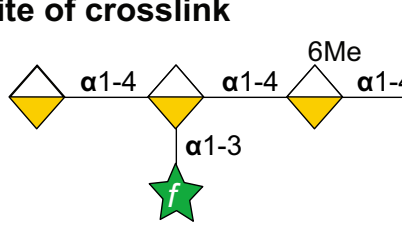

Chain E
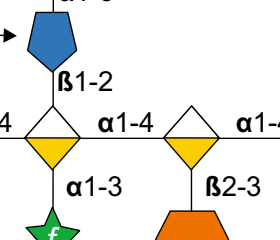
$\alpha 1-3$

a1-3'

$f$ and Araf

$F$

B1-5

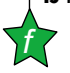

Nominal Molecular Mass $=5094$ Da Chain D

Chain C
c Ace $\mathrm{A} \square$
D-Api
L-Ara \{
Dha
L-Fuc
D-GalA
D-GlcA
Kdo
L-Rha $R$
D-Xyl \{

Fig. 1 (See legend on previous page.) 
the formation of the borate diester cross-linked RG-II dimer (Fig. 1b) [35]. Numerous studies have indicated the importance of RG-II in plant fitness and development and also demonstrate the relevance of glycan structures and glycoform variants in biology [19, 36-41].

In this work, we use RG-II as a case study to present a basic workflow and a set of complementary techniques that are necessary for the characterization of complex carbohydrates. RG-II presents a considerable challenge to the analyst because of its diverse glycosyl composition, the diversity of its glycosidic linkages, and the subtle structural variations that occur in different plants (Fig. 1b). We describe methods to extract and isolate RG-II from different sources and further detail how to characterize complex carbohydrates using established liquid chromatography, mass spectrometry (MS), and nuclear magnetic resonance spectroscopy (NMR) techniques. We use our characterization methods to introduce some caveats specific to RG-II analysis that may inform studies of other glycobiology researchers. Such methodologies are broadly applicable for the structural characterization of diverse pectic and hemicellulosic polysaccharides typically encountered in biomass obtained from different plants.

\section{Results and discussion}

\section{Release of RG-II from the plant cell wall}

RG-II accounts for between 1 and 5\% by mass of the polysaccharides present in the primary cell walls of vascular plants [32]. RG-II can be extracted from isolated plant cell walls, which are prepared from plant tissues as their alcohol insoluble residues (AIR), using two related methods (see Fig. 1a). In our first protocol, high molecular mass pectins are solubilized by treating the AIR with $50 \mathrm{mM}$ ammonium oxalate (Fig. 1a, Oxalate Extraction) [42]. Ammonium oxalate chelates divalent cations and solubilizes pectins held in the wall by calcium cross-links. Other chelators, including ethylenediaminetetraacetic acid (EDTA) and 1,2-Cyclohexylenedinitrilotetraacetic acid (CDTA), have also been used to solubilize cell wall pectins but have the disadvantage that they are not readily removed by dialysis against water, which may complicate further analyses [43]. The oxalate-solubilized pectins are then fragmented with endopolygalacturonase (EPG), which generates a mixture of RG-I, RG-II, and OGAs (Fig. 1a, EPG digestion). Ammonium oxalate extraction typically improves yields for samples such as duckweed AIR, while for other sources of RG-II including celery and Arabidopsis AIR, the ammonium oxalate extraction can be omitted. In this case, we use our second protocol, where we treat the AIR directly with EPG [44], which solubilizes RG-II together with RG-I and OGAs by fragmenting the HG backbone of pectic molecules (Fig. 1a).

\section{Isolation of RG-II from red wine}

Red wine, which contains $\sim 100 \mathrm{mg} / \mathrm{L}$ of RG-II, is a convenient source for isolating RG-II in gram amounts as the yeast involved in fermentation is unable to break down RG-II [45]. Red wine is first concentrated six-fold on a rotary evaporator and then ethanol is added to a final concentration of $80 \%(\mathrm{v} / \mathrm{v})$. The mixture is kept overnight at $4{ }^{\circ} \mathrm{C}$ and the precipitate that forms is collected by centrifugation. The precipitate is dissolved in water and extensively dialyzed (3500 Da molecular weight cutoff (MWCO)) against water, and freeze-dried. This precipitate contains intact RG-II dimer, as well as arabinogalactan (AGP)/RG-I, oligogalacturonides (OGAs), and yeast-derived mannan [46].

\section{Isolation of RG-II by size-exclusion chromatography}

The EPG-solubilized material from cell walls and red wine precipitate contain a mixture of polysaccharides that can be separated by size-exclusion chromatography (SEC) to obtain material highly enriched in RG-II (Fig. 2). SEC of the EPG-solubilized wall extracts also gives fractions that contain RG-I and OGAs (Fig. 2a, b). In contrast, the wine precipitate (Fig. 2c) also gives fractions containing arabinogalactan proteins (AGPs), yeast mannan [46], and OGAs [45]. When large amounts of material (500-700 $\mathrm{mg}$ ) are available, the precipitate from wine and the EPG-solubilized material from AIR can be fractionated by preparative scale SEC on a conventional Sephadex G-75 SEC column $(4 \times 100 \mathrm{~cm})$ (Fig. 2a, c). In this case, large fractions $(12 \mathrm{~mL})$ are collected and analyzed colorimetrically for the presence of uronic acids [47]. If the amount of available pectic material is $<100 \mathrm{mg}$, as is the case for our small-scale preparations of duckweed RG-II, we use a Superdex 75 Increase GL10300 column coupled with refractive index detection (Fig. 2b). We typically fractionate between 5 and $10 \mathrm{mg}$ per run to maintain the separation efficiency of the column. RG-II monomer and dimer are readily resolved on

\footnotetext{
(See figure on next page.)

Fig. 2 Isolation of RG-II using size-exclusion chromatography (SEC). a EPG-solubilized material (200-300 mg) from celery AIR in $50 \mathrm{mM}$ NaOAc pH 5 was fractionated using a preparative Sephadex G-75 SEC column $(1 \mathrm{~m} \times 4 \mathrm{~cm})$. Fractions were assayed colorimetrically for uronic acids $\left(\mathrm{A}_{530}\right)$. $\mathbf{b}$ SEC of the EPG-treated oxalate-soluble fraction from $W$. repanda fractionated on a Superdex 75 Increase column monitored using refractive index (RI) detection. c The ethanol precipitated material from red wine $(\sim 500 \mathrm{mg})$ separated using a preparative Sephadex G-75 SEC column (1 m $\times 4 \mathrm{~cm})$ and assayed colorimetrically for uronic acids $\left(\mathrm{A}_{530}\right)$
} 


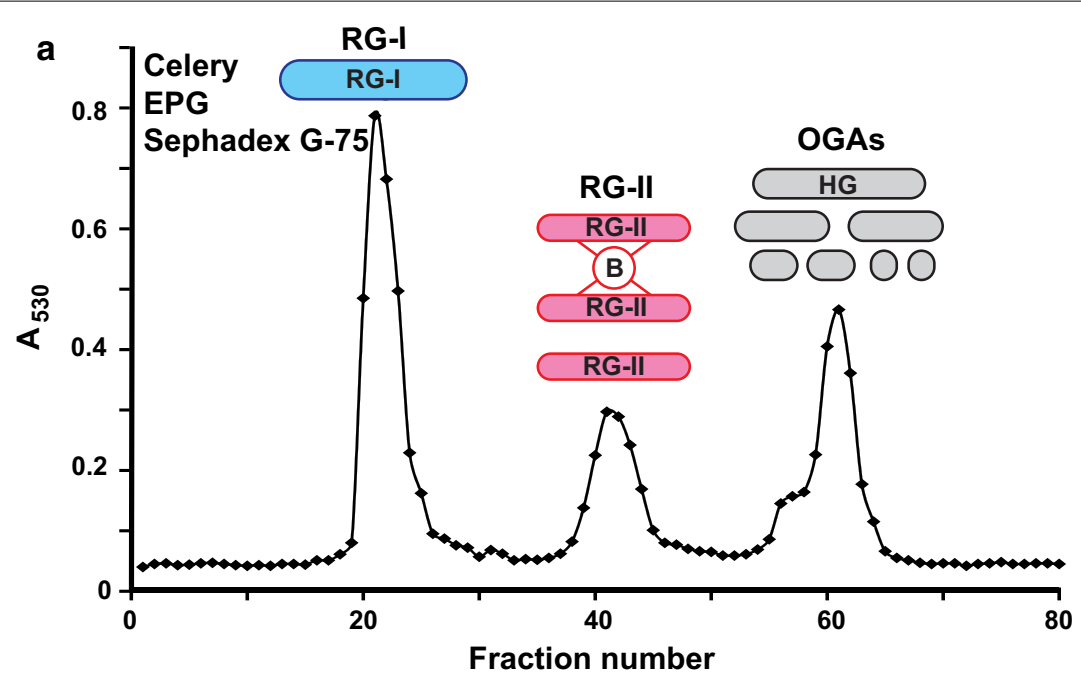

b
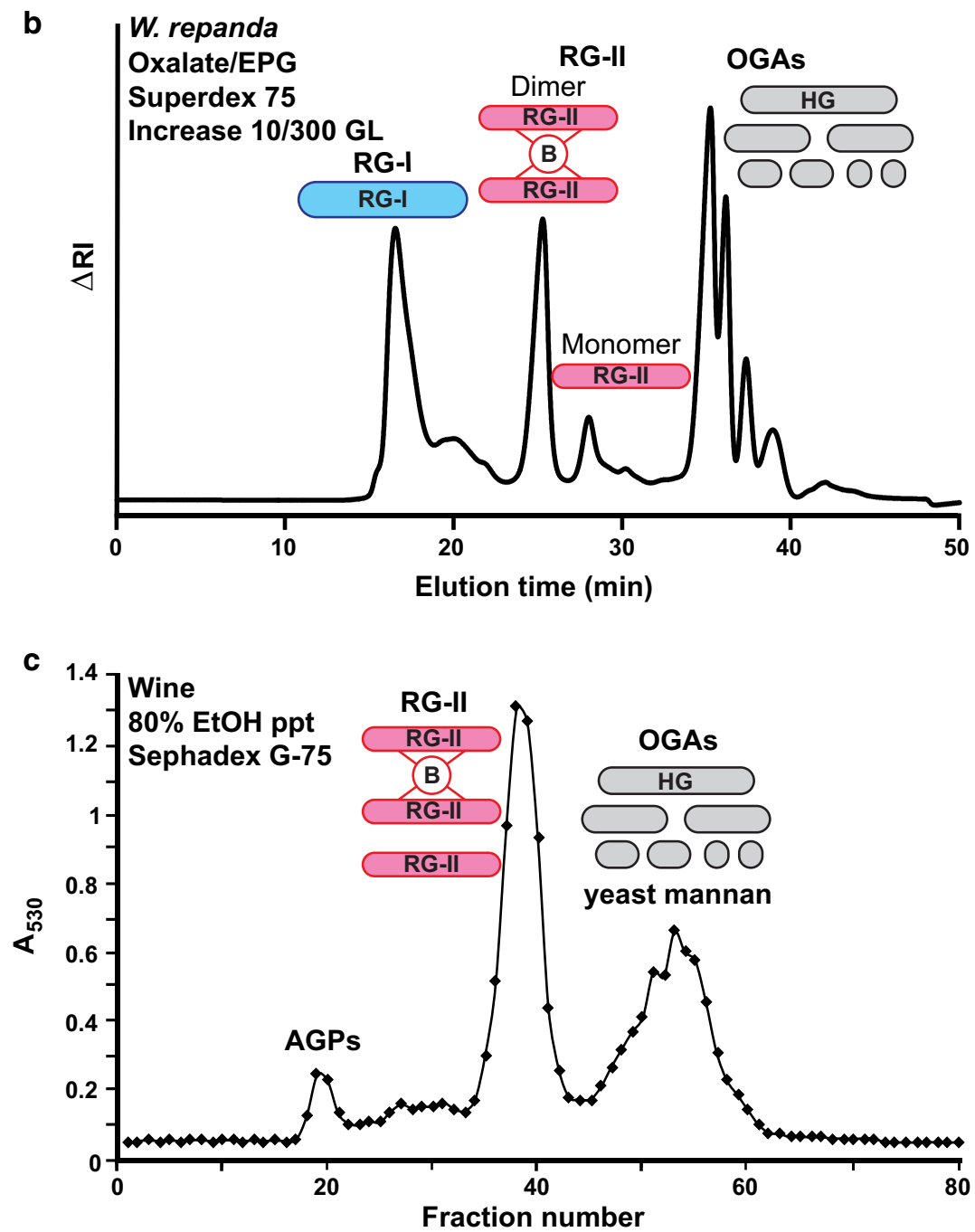

Fig. 2 (See legend on previous page.) 
the Superdex 75 column but not on the Sephadex G-75 column. Fractionation is complete in less than $1 \mathrm{~h}$ with the Superdex column and thus is much faster than the Sephadex G-75 column, which takes at least 12 h. However, approximately 50 -fold more sample can be fractionated in a single run on the Sephadex G-75 column.

SEC separates compounds largely on the basis of their molecular mass and hydrodynamic volume, thus it is common for similarly sized molecules to co-elute with the target molecule during purification. It has been previously observed that the "crude RG-II" obtained from apple juice by ethanol precipitation was contaminated with galactan and arabinan [34], indicating that presence of diverse polysaccharides may be a common problem that affects the purity of RG-II preparations. Indeed, glycosyl residue composition analysis of the RG-II fraction isolated from celery AIR by preparative scale Sephadex G-75 SEC (Fig. 2a) showed that it contained far more galactose than expected based on the known structure of this pectic polysaccharide (Additional file 1: Table S1). We then found that the celery RG-II was contaminated with a galactan, which can be removed by anionexchange chromatography (Additional file 1: Fig. S1 and Table S1). Thus, it is important to perform glycosyl residue composition analysis to determine the composition of glycans in fractions and to identify the presence of undesired components based on deviations from the expected ratios of monosaccharides for a given polysaccharide. Demonstrating purity and homogeneity can be challenging for other pectic polysaccharides, most notably RG-I, which often exists as a family of polysaccharides that differ in the abundance and types of side chains attached to the backbone [48]. In addition, linkage analysis can also provide information concerning the particular linkage of suspected contaminant monosaccharides which would indicate whether the particular monosaccharide is derived from RG-II or a different polysaccharide. Anion-exchange and size-exclusion chromatography alone or combined with additional enzymatic treatments that degrade the undesired component [34] may be sufficient to obtain homogeneous RG-II when purifying RG-II from fruit juices or plant cell wall extracts. Similar approaches for RG-I may result in the enrichment of a particular familiar of polymers with similar glycosyl compositions.

\section{Determining the abundance of the RG-II dimer and monomer}

Most RG-II exists as a dimer in the plant cell wall. This dimer consists of two RG-II molecules that are covalently linked together by a borate diester formed between the apiosyl substituent of side chain A of each monomer (Fig. 1b). RG-II monomers and dimers are readily separated using a Superdex 75 10/300 column [35, 49]. We have found that they also separate on the recently introduced Superdex 75 Increase HR10/300 column, although their retention times may increase slightly. The amount of RG-II required for detection is determined in large part by the sensitivity of the refractive index detector used. In our experience, $50 \mu \mathrm{g}$ of RG-II is sufficient for these analyses. This is fourfold less than the amounts (200 $\mu \mathrm{g}$ RG-II) we previously used $[35,49]$, and has increased our ability to compare the effects of different conditions including $\mathrm{pH}$, buffers, and cations on dimer formation in vitro [33]. The absolute and relative abundances of RG-II monomer and dimer are estimated from their peak areas with respect to the known injection amount.

\section{Determining the molecular mass of RG-II using SEC with multi-angle static light scattering}

Determining the molecular mass of polysaccharides is challenging as they are typically polydisperse polymers with a broad distribution of molecular weights and have a tendency to form aggregates. RG-II isolated from cell wall residues is an exception to this limitation as it is monodisperse and there is no evidence that it forms aggregates. These characteristics make RG-II an ideal molecule for polysaccharide molecular weight determination. The technique we used for this study involves SEC coupled to a multi-angle laser light scattering (MALS) detector and a refractive index (RI) detector (SEC-MALS). SEC-MALS provides an absolute molecular weight without reference to standards. However, these analyses first require that the specific refractive index increment $(d n / d c)$ value of the molecule under investigation is determined. The $d n / d c$ value is dependent on the composition of the polysaccharide of interest, the eluents used for SEC, temperature, and the wavelength of the light source of the refractive index detector. Thus, the $d n / d c$ value should be calculated for each SEC-MALS system and polysaccharide. However, if it is not possible to obtain a pure polysaccharide for these calculations, published $d n / d c$ values may prove to be adequate [50]. Here, purified celery RG-II monomer was used to calculate the $d n / d c$ value, which was determined to be $0.122 \pm 0.003 \mathrm{mg} / \mathrm{mL}$.

Our SEC-MALS data (Table 1) show that the molecular mass of the celery RG-II monomer $\left(M_{w} 4606 \mathrm{Da}\right)$ is less than that of the similarly prepared monomer from red wine $\left(M_{w} 4971 \mathrm{Da}\right)$. These values are close to the calculated nominal mass of 5094 Da for the full RG-II monomer structure shown in Fig. 1b, which is typical of wine RG-II. Celery RG-II lacks the Araf and two Rha that are attached to the Ara $p$ of wine RG-II on side chain B (Fig. 1b) [33]. Thus, our SEC-MALS results are in general agreement with the structural differences between 
Table 1 The molecular masses of celery and wine RG-II obtained by SEC-MALS

\begin{tabular}{lllll}
\hline Source & RG-II & Mw (g/mol) & Mn (g/mol) & $\begin{array}{l}\text { Polydispersity } \\
\text { (Mw/Mn) }\end{array}$ \\
\hline Celery & Dimer & $9404 \pm 143$ & $9343 \pm 176$ & $1.01 \pm 0.00$ \\
& Monomer & $4606 \pm 246$ & $4556 \pm 241$ & $1.02 \pm 0.02$ \\
Wine & Dimer & $10,470 \pm 428$ & $10,378 \pm 296$ & $1.01 \pm 0.01$ \\
& Monomer & $4971 \pm 307$ & $4881 \pm 186$ & $1.01 \pm 0.03$ \\
\hline
\end{tabular}

Data are averages and SD of at least three runs

the celery and wine RG-II glycoforms. The native RG-II dimer isolated from wine and celery gave a polydispersity index of $\sim 1$, a value characteristic of monodisperse polymers, which suggests a uniform structure for the RG-II dimer in plant cell walls. SEC-MALS analysis also provides useful information in the study of other pectic polysaccharides, including the polydispersity and $M_{w}$ of pectin and pectin fragments generated by enzymatic or selective chemical treatments.

\section{Glycosyl residue composition of RG-II}

Once an RG-II-enriched fraction has been obtained by SEC, its glycosyl residue composition must be determined to verify the presence of RG-II and if substantial amounts of undesired polysaccharides are present, as discussed above. There is no single protocol that can be used to simultaneously detect and quantify all of the glycoses that comprise RG-II due to the chemical diversity of its constituent monosaccharides (Fig. 1b) [44, 51, 52]. Gas-liquid chromatography (GLC) analysis of the alditol acetate derivatives [53] is suitable for identifying and quantifying neutral glycoses and aceric acid (3-C-carboxy-5-deoxy-L-xylose, AceA; Table 2; Additional file 1: Fig. S2a).

Two of the glycoses within RG-II, 2-keto-3-deoxymanno-octulosonic acid (Kdo) and 3-deoxy-D-lyxo2-heptulopyranosylaric acid (Dha), are degraded by the hot $2 \mathrm{M}$ trifluoroacetic acid (TFA) treatment that is used to hydrolyze the glycosidic bonds and release the monosaccharides for the preparation of alditol acetate derivatives. Several modifications to this procedure are required to detect Kdo and Dha as their alditol acetates $[51,54]$. Furthermore, it is difficult to quantify Dha due to a current lack of a commercially available standard. The alditol acetate procedure can also be modified to analyze hexuronic acids [55], but quantification can be challenging because of incomplete conversion of GalA to its corresponding lactone, which is subsequently reduced to galactitol and acetylated. Thus, GalA, glucuronic acid (GlcA), Kdo, and Dha are typically analyzed as their trimethylsilyl methyl-ester methyl glycoside (TMS) derivatives by GLC with electron impact mass
Table 2 Partial glycosyl residue compositions of purified wine and celery RG-II

\begin{tabular}{lll}
\hline Glycose & $\begin{array}{l}\text { Wine RG-II (Sephadex } \\
\text { G-75 fraction) } \\
\text { Mol\% }\end{array}$ & $\begin{array}{l}\text { Celery RG-II (Q-Sepharose } \\
\mathbf{1 . 5} \text { M imidazole fraction) }\end{array}$ \\
\hline MeFuc & $2.9 \pm 0.1$ & \\
Rha & $16.3 \pm 0.7$ & $3.9 \pm 0.4$ \\
Fuc & $1.8 \pm 0.0$ & $14.9 \pm 0.9$ \\
MeXyl & $2.9 \pm 0.2$ & $2.9 \pm 0.1$ \\
Ara & $17.6 \pm 1.0$ & $4.0 \pm 0.4$ \\
Api & $3.6 \pm 0.3$ & $14.1 \pm 1.5$ \\
AceA & $1.2 \pm 0.1$ & $3.9 \pm 0.8$ \\
Gal & $17.9 \pm 1.2$ & $1.3 \pm 0.3$ \\
Glc & $1.4 \pm 0.1$ & $10.7 \pm 1.0$ \\
GalA & $29.2 \pm 1.2$ & $0.2 \pm 0.0$ \\
GlcA & $5.2 \pm 2.6$ & $39.9 \pm 3.8$ \\
\hline
\end{tabular}

Quantification of neutral sugars and AceA was performed using alditol acetate derivatives. Quantification of uronic acids was performed using HPAEC-PAD. All values are expressed as a molar percentage and represent the average data from three replicates. See Additional file 1: Figure S2 for representative spectra

${ }^{a}$ The RG-II fraction isolated by SEC of the material solubilized by EPG treatment of celery petiole AIR (see Fig. 2 in the main text)

${ }^{b}$ The celery RG-Il obtained by SEC was purified by anion-exchange chromatography. A solution of the celery RG-II $(400 \mathrm{mg})$ in $10 \mathrm{mM}$ imidazole$\mathrm{HCl} \mathrm{pH} 7$ was applied to a column $(15 \mathrm{~cm} \times 2 \mathrm{~cm} ; 47.1 \mathrm{~mL}$ column volume) of fast flow DEAE-Sepharose (Cytiva, USA). The column was eluted stepwise with $10 \mathrm{mM}$ imidazole-HCl pH 7 (3 column volumes), $100 \mathrm{mM}$ imidazole- $\mathrm{HCl} \mathrm{pH} 7$ (3 column volumes), and then with $1.5 \mathrm{M}$ imidazole- $\mathrm{HCl}, \mathrm{pH} 7$ (4 column volumes). RG-II ( 95\% dimer, $295 \mathrm{mg}$ ) eluted with $1.5 \mathrm{M}$ imidazole-HCl. A galactose-rich material $(73 \mathrm{mg})$ eluted with $10 \mathrm{mM}$ imidazole- $\mathrm{HCl}$

spectrometry (GLC-EI-MS, see Fig. 3a, b) [56]. The Dha and Kdo derivatives have diagnostic mass spectra, which are used to confirm the identities of their peaks (Fig. 3c). The TMS derivatives of other glycoses characteristic of RG-II including AceA, 2-O-methyl-fucose (2MeFuc), 2-O-methyl xylose (MeXyl), and Api also give mass spectra that aid in their identification (Fig. 3c). Thus, these sugars can be used to identify RG-II containing peaks separated by SEC. Methyl-etherified GalA residues, which are present in RG-II from several plants, are challenging to quantify as they must be converted to their acetylated 6,6'-di-deuterio-galactitol derivatives prior to analysis by GLC-EI-MS [33]. Given the aforementioned complications, monosaccharide quantification may vary between samples but is nonetheless an indication of the composition of the saccharide of interest. Thus, a comprehensive description of all the RG-II monosaccharides requires GLC-EI-MS analyses of the alditol acetate (Table 2; Additional file 1: Fig. S2a) and TMS derivatives (Fig. 3) and can be further complemented by HPAECPAD analysis (Additional file 1: Fig. S2b) of the monosaccharides released by TFA hydrolysis if standards are available [42]. 

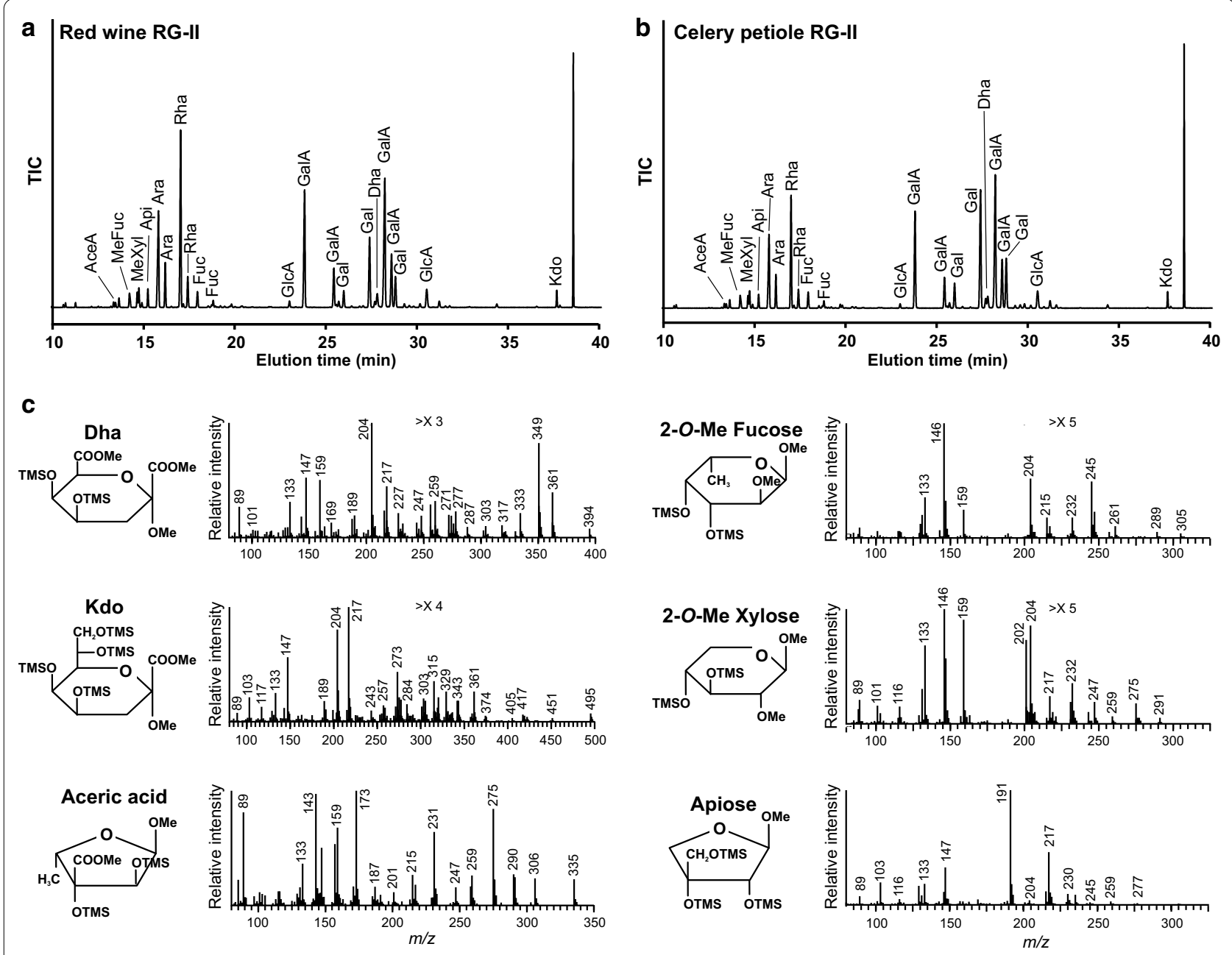

Fig. 3 GLC-El-MS total ion current profiles and selected mass spectra of the trimethylsilyl methyl-ester methyl glycoside derivatives of the monosaccharides generated from RG-II. a, b The GLC-EI-MS total ion current (TIC) profile of the TMS derivatives generated from wine (a) and celery (b) RG-II. The identity of the monosaccharide derivative in each peak is shown. The peak eluting at $~ 39$ min is the TMS derivative of myo-inositol used as an internal standard. c The El mass spectrum of selected monosaccharide derivatives generated from wine RG-II. The multiplication factor $(>X)$ used to expand selected regions of each mass spectrum is shown

The glycosidic bonds of glycosyl residues in other pectins, notably RG-I, also exhibit differences in their susceptibility to hot acids. Thus, a compromise is often required between the amounts of a glycose released by hydrolysis and the amounts that are subsequently degraded by the hot acid [57]. Nevertheless, such differences in acid lability can be exploited in structural studies of RG-I. For example, selective acid hydrolysis of RG-I has been used to remove most of the Araf-containing side chains and render the polysaccharide backbone susceptible to both rhamnogalacturonan hydrolase and lyase [58]. Similarly, selective removal of Api residues by autohydrolysis renders the backbone of apiogalacturonans susceptible to the action of endopolygalacturonase [59].

\section{Glycosyl-linkage analysis of the B side chain of RG-II}

It is now accepted that even though the glycosyl sequence of RG-II is largely conserved, the structures of the $\mathrm{A}$ and $\mathrm{B}$ side chains are not identical in all plants (Fig. 1b) [33, 60-63]. Thus, a complete description of RG-II requires the characterization of these side chains. To this end, the A and B side chains are released from the RG-II backbone using selective hydrolysis with dilute aqueous TFA and characterized by mass spectrometry $[60,61,64]$. In our laboratory, we release side chain B by treating RG-II for $16 \mathrm{~h}$ at $40{ }^{\circ} \mathrm{C}$ with $0.1 \mathrm{M}$ TFA. Small amounts of the A side chain may also be released with this treatment [60]. However, side chain A is released more effectively by treating RG-II for 
$1 \mathrm{~h}$ at $80{ }^{\circ} \mathrm{C}$ with $0.1 \mathrm{M}$ TFA [60]. This treatment also releases side chain $B$ but a substantial amount of the acid-labile terminal Araf residue is hydrolyzed at the higher temperature.

Side chain B glycoforms differ in the number and type of glycoses attached to the Arap residue (Fig. 1b). For example, no sugars are attached to the Arap in celery RG-II [12], whereas the Ara $p$ is substituted at $O-2$ with Rha or the disaccharide Araf-Rha- and with Rha at $O-3$ in the RG-II from many other plants (Fig. 1b) [61, 64, 65]. In a previous study, we reported that side chain $B$ is a heptasaccharide in RG-II produced by several duckweeds, including Wolffiella repanda [42]. Matrix-assisted laserdesorption time-of-flight mass spectrometry (MALDITOF-MS) together with glycosyl residue composition analysis indicated that a single Rha residue is attached to the Ara $p$ [42]; however, it was not determined if the Rha is attached to $O-2$ or $O-3$ of the Arap. Electrospray (ESI) MS and MS ${ }^{\mathrm{n}}$ in the positive ion mode is an established technique used to determine the mass of oligosaccharides, their glycosyl sequences, linkage positions, and the locations of $O$-acetyl and $O$-methyl substituents [66]. To this end, B side chain-enriched materials were generated from $W$. repanda and celery RG-II by treatment for $16 \mathrm{~h}$ with $0.1 \mathrm{M}$ TFA at $40{ }^{\circ} \mathrm{C}$ and then isolated by SEC using a Superdex 75 column. The B side chain material was methylated using solid $\mathrm{NaOH}$ and methyl iodide in DMSO [67]. ESI-MS of the methylated products revealed that the predominant oligosaccharide from W. repanda (Fig. 4a) gave a $[\mathrm{M}+\mathrm{Na}]^{+}$ion at $m / z 1143$, which is consistent with an oligosaccharide composed of two Rha, one 2MeFuc, one Ara, one Gal, and AceA. The corresponding celery oligosaccharide gave a $[\mathrm{M}+\mathrm{Na}]^{+}$ ion at $m / z 969$ (Fig. 4c), which is consistent with an oligosaccharide composed of one Rha, one $2 \mathrm{MeFuc}$, one Ara, one Gal, and AceA. These masses are 160 atomic mass units lower than expected and correspond to the loss of a methylated pentose. We suspected that this was caused by the base-catalyzed degradation of the reducing Api during the methylation reaction. To confirm this, the W. repanda and celery side chain B-enriched fractions were treated with $\mathrm{NaBH}_{4}$ to convert the 3'-linked Api to 3'-linked apiitol. An apiitol at the former reducing end should not be susceptible to base degradation. The oligosaccharide-alditols were then per-O-methylated. The ESI-MS of the methylated oligosaccharide-alditol from $W$. repanda $(m / z 1319$, Fig. $4 \mathrm{~b})$ is consistent with a $B$ side chain heptasaccharide composed of two Rha, one 2MeFuc, one Ara, one Gal, one AceA, and apiitol. The celery B side chain derivative $(m / z 1145$, Fig. 4 d) is composed of one Rha, one $2 \mathrm{MeFuc}$, one Ara, one Gal, one AceA, and apiitol. Thus, it is likely that the reducing form of side chain B undergoes base-catalyzed degradation during methylation with solid $\mathrm{NaOH}$ in DMSO. As such, we recommend that glycosyl-linkage analyses of oligosaccharides, irrespective of the polysaccharide they are generated from, are performed with the oligosaccharidealditol rather than their reduced counterparts.

The $\mathrm{ms}^{2}$ spectra obtained by fragmenting the sodiated adducts of the methylated $B$ side chains generated from W. repanda and celery RG-II (Fig. 4) are consistent with the known glycosyl sequences of side chain B from other plants (see Fig. 1b). However, the spectra contained few if any fragment ions that could be used to unambiguously determine the substitution pattern of the Arap. Thus, we hydrolyzed the methylated material with $2 \mathrm{M}$ TFA and converted the released methylated glycoses to their corresponding methylated alditols by reduction with $\mathrm{NaBD}_{4}$ [53]. These alditols were acetylated to give the per$O$-methylated alditol acetate derivatives and analyzed by GLC-EI-MS (Additional file 1: Fig. S3). The identification of 1,2,5-tri-O-acetyl-3,4-di-O-methylarabinitol and 1,5-di-O-acetyl-2,3,4-tri-O-methylrhamnitol established that in W. repanda RG-II the Arap is substituted at $O-2$ with Rha.

\section{The non-glycosyl modifications of side chains A and B of RG-II}

In addition to its utility for determining glycosyl composition and linkage, electrospray ionization MS and $\mathrm{MS}^{\mathrm{n}}$ in the positive ion mode have become the method of choice to obtain additional information concerning the precise locations of $O$-acetyl and $O$-methyl substituents present on saccharides [60, 61]. ESI-MS analyses showed that the mono- $O$-acetylated nonasaccharide $(\mathrm{m} / \mathrm{z}$ 1399) accounts for a large portion of the B side chain that is released by treatment of red wine RG-II with $0.1 \mathrm{M}$ TFA for $16 \mathrm{~h}$ at $40{ }^{\circ} \mathrm{C}$ (Fig. 5a). Small amounts of the di$O$-acetylated chain B $(m / z 1441)$ are also discernible. The side chain B spectrum also contains ions corresponding to the loss of a pentose $(\mathrm{m} / \mathrm{z} 132)$ and a 6-deoxyhexose $(\mathrm{m} / \mathrm{z} 146)$ from the mono- $\mathrm{O}$-acetylated nonasaccharide. It is not known if these smaller side chain B oligosaccharides occur naturally in wine RG-II or are generated during treatment with warm dilute TFA. Side chain B is also released by treating RG-II with $0.1 \mathrm{M}$ TFA for $1 \mathrm{~h}$ at $80^{\circ} \mathrm{C}$, but a substantial amount of the acid-labile terminal Araf residue is hydrolyzed at the higher temperature $\left(\mathrm{m} / z 1267\right.$ in Fig. 5d). Compared to the $\mathrm{ms}^{2}$ spectrum of the unacetylated side chain B nonasaccharide (Fig. 5b), the $\mathrm{ms}^{2}$ spectrum of the mono-O-acetylated side chain $\mathrm{B}$ nonasaccharide $(\mathrm{m} / \mathrm{z} 1399$; Fig. 5c) contains ions at $\mathrm{m} / \mathrm{z}$ 461,825 , and 943 , suggesting that an $O$-acetyl group is located on the MeFuc or the Gal residue. The $\mathrm{ms}^{2} \mathrm{spec}-$ trum of the acetylated side chain B contains ions at $\mathrm{m} / \mathrm{z}$ 901 and 857 (Fig. 5c) that are formed by loss of $202 \mathrm{amu}$ 


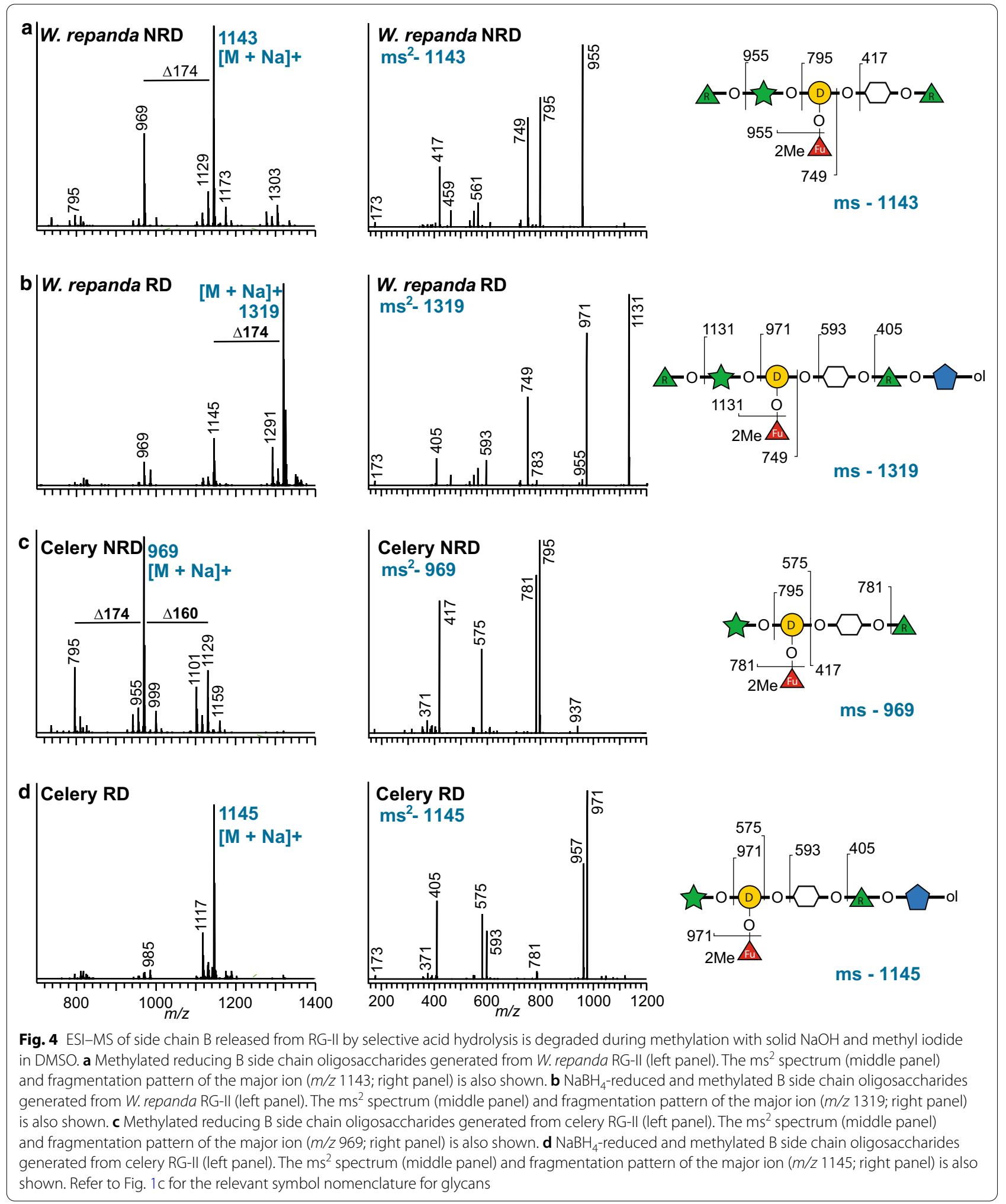



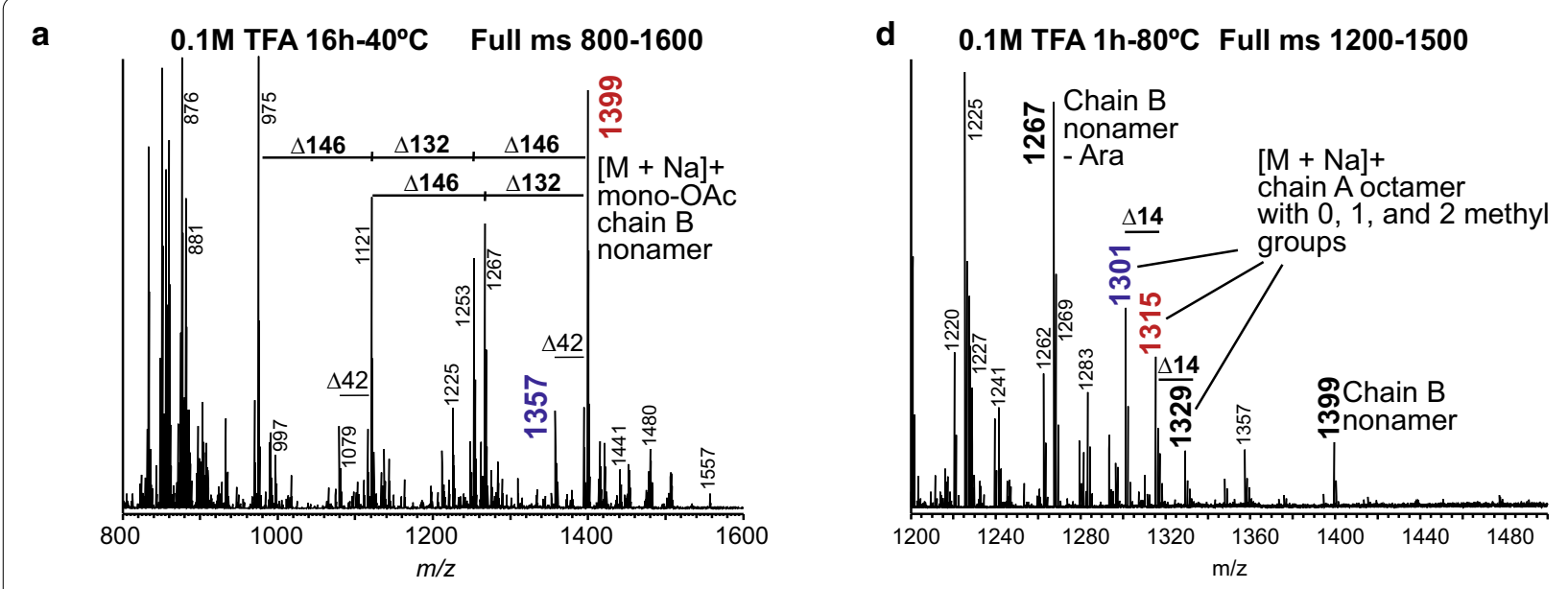

b Wine RGII-B-2MeFuc $\mathrm{ms}^{2} 1357$
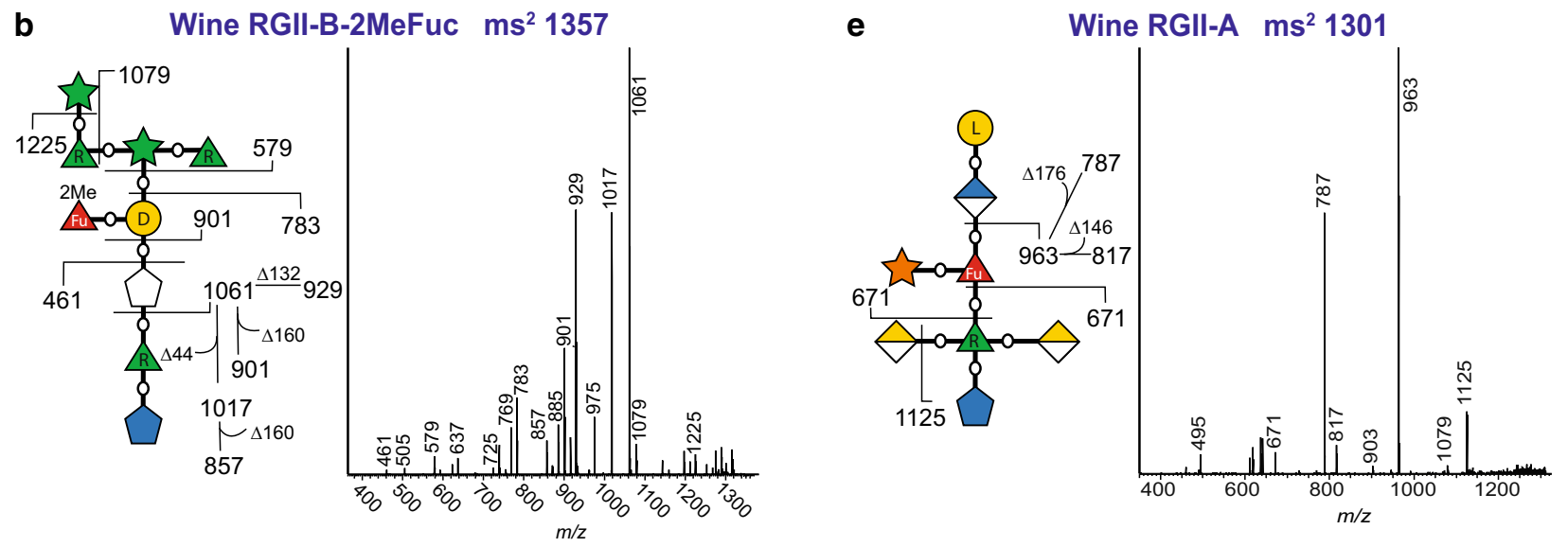

c

Wine RGII-B-Ac2MeFuc ms $^{2} 1399$
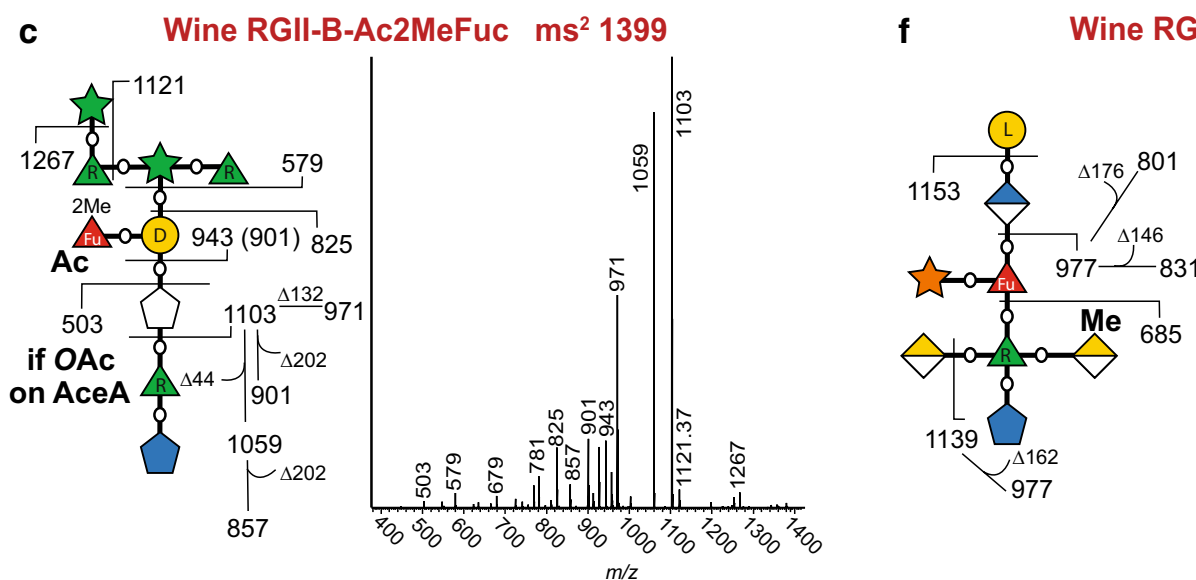

Fig. 5 Locating the $O$-acetyl groups of side chain B and the methyl-ethers of side chain A using ESI-MS. a The ESI mass spectrum of the oligosaccharides generated by treating wine RG-II with $0.1 \mathrm{MTFA}$ for $16 \mathrm{~h}$ at $40^{\circ} \mathrm{C}$ (side chain B-enriched). $\Delta 146$ corresponds to a Rha residue, $\Delta 132$ corresponds to an Ara residue, and $\triangle 42$ corresponds to an OAc group. $\mathbf{b}$ The $\mathrm{ms}^{2}$ spectra of the B side chain nonasaccharide $(\mathrm{m} / \mathrm{z} 1357)$ and its fragmentation pattern. $\mathbf{c}$ The $\mathrm{ms}^{2}$ spectra of the B side chain mono-O-acetylated nonasaccharide $(\mathrm{m} / \mathrm{z} 1399)$ and its fragmentation pattern. $\mathbf{d}$ The ESI mass spectrum of the oligosaccharides generated by treating wine RG-II with $0.1 \mathrm{M}$ TFA for $1 \mathrm{~h}$ at $80^{\circ} \mathrm{C}$ (side chain A-enriched). $\triangle 14$ corresponds to a methyl group. $\mathbf{e}$ The $\mathrm{ms}^{2}$ spectra of the A side chain octasaccharide $(\mathrm{m} / \mathrm{z} 1301)$ and its fragmentation pattern. $\mathbf{f}$ The $\mathrm{ms}^{2}$ spectra of the A side chain mono-methylated octasaccharide $(\mathrm{m} / \mathrm{z} 1315)$ and its fragmentation pattern. Refer to Fig. 1c for the relevant symbol nomenclature for glycans 
(methyl 6-deoxy hexose $+1 O$-acetyl group) from the ion at $m / z 1103$. The ions at $m / z 901$ and 857 are also present in the $\mathrm{ms}^{2}$ spectrum of the unacetylated nonasaccharide (Fig. 5b) and correspond to the loss of $160 \mathrm{amu}$ (methyl 6-deoxy hexose) from the ion at $m / z$ 1103. Thus, it is likely that the $2 \mathrm{MeFuc}$ residue is mono- $\mathrm{O}$-acetylated. The presence of a low abundance ion at $m / z 503$ also suggests that in the mono- $O$-acetylated side chain B nonasaccharide, a small portion of the AceA is substituted with a single $\mathrm{O}$-acetyl group (Fig. 5c). Thus, the $\mathrm{O}$-acetylated $\mathrm{B}$ side chain from wine contains an $\mathrm{O}$-acetyl group on two different sugars.

The glycosyl sequence of side chain A is largely conserved. However, the number of methyl groups attached to this side chain often differs between plants $[33,60$, 61]. For example, red wine RG-II side chain A contains either 0,1 , or 2 methyl groups (Fig. $5 \mathrm{~d}$ ). The $\mathrm{ms}^{2}$ spectrum of the mono-O-methylated A side chain contains ions at $m / z 685$ and 1139 (Fig. 5f). These data, when taken together with the $\mathrm{ms}^{2}$ spectrum of wine side chain A lacking methyl groups (Fig. 5e), are consistent with the presence of a mono-O-methylated GalA $[33,61]$.

Techniques based on selective acid hydrolysis can be applied to the analyses of glycosyl and non-glycosyl substituents in other pectic polysaccharides. Selective acid hydrolysis is also an established method for fragmenting pectins. Moreover, numerous glycanases, many of them produced commercially, including exo- and endo-arabinanases and galactanases, galacturonases, and rhamnogalacturonases, are available and are now being widely used as tools to elucidate the structural features of pectins from diverse plants.

\section{NMR spectroscopy provides insight into RG-II methylation and acetylation}

We described how to use MS techniques to characterize the A and B side chains of RG-II, but the complexity and chemical diversity of RG-II is not limited to these two side chains. Furthermore, MS-based techniques for characterizing oligosaccharides have the disadvantage of being destructive and typically require a prior enzymatic or chemical treatment to generate molecules suitable for analyses.

Plant polysaccharides are often further substituted by the addition of base-labile $O$-acetyl and methyl-esters and base-stable methyl-ethers, which adds to the complexity of their structures and may affect their functionality [21, 68]. RG-II contains mono-O-acetylated MeFuc and AceA [69] and often contains methyl-esterified GlcA on side chain A and methyl-esterified GalA in its backbone [33, 60, 61]. RG-II also contains three methyl-etherified glycoses: MeFuc, MeXyl, and MeGalA [33, 61]. These non-carbohydrate modifications are an additional source of structural diversity between RG-II glycoforms isolated from different plant species. In contrast to MS-based techniques, nuclear magnetic resonance spectroscopy (NMR) is a non-destructive technique particularly useful for characterizing intact glycans and their non-carbohydrate substituents. Here, we describe how ${ }^{1} \mathrm{H}-\mathrm{NMR}$ can be used to identify RG-II glycoses and non-glycosyl modifications.

The ${ }^{1} \mathrm{H}$-NMR spectra of the native wine RG-II monomer and dimer (Fig. 6a, c) contain intense signals that correspond to methyl-ester protons $(\delta 3.81$ and $3.84 \mathrm{ppm})$ and $O$-acetyl protons $(\delta 2.16$ and $2.22 \mathrm{ppm})$. However, the presence of acetyl and methyl-esters complicate the ${ }^{1} \mathrm{H}$-NMR spectra of RG-II as they may cause changes in the chemical shifts of anomeric and ring protons of a monosaccharide. The methyl-ester and $O$-acetyl proton signals may also overlap with or obscure the signals of a glycosyl residue. Thus, to facilitate our NMR structural analysis, it was important to de-esterify RG-II. Since methyl and acetyl-esters are base labile, we routinely use cold $100 \mathrm{mM} \mathrm{NaOH}$ to de-esterify pectic polysaccharides, while minimizing the possibility of basecatalyzed degradation.

Somewhat unexpectedly, our ${ }^{1} \mathrm{H}-\mathrm{NMR}$ spectroscopic analyses showed that even though the base treatment fully hydrolyzed acetyl- and methyl-esters from the RG-II monomer (Fig. 6a, b), base treatment of the RG-II dimer hydrolyzed the methyl-esters but only resulted in partial de-O-acetylation of the dimer (Fig. 6c, d; Table 3). One signal corresponding to an $O$-acetyl group $(\delta 2.26 \mathrm{ppm})$ remained after base treatment of the RG-II dimer. Our MALDI-TOF-MS spectra of side chain $B$ generated from the monomer, dimer, and their base-treated counterparts (Additional file 1: Fig. S4) provide additional evidence that side chain $\mathrm{B}$ is only partially de-O-acetylated by base treatment of the RG-II dimer. Together, these data show that in the dimer, the side chain $\mathrm{B} O$-acetyl groups are not completely hydrolyzed by treatment with alkali.

The removal of $\mathrm{O}$-acetyl groups from the RG-II monomer revealed the presence of signals in the ${ }^{1} \mathrm{H}-\mathrm{NMR}$ spectrum that we assigned to the H3 and H3' $(\delta 1.95$ and $2.20 \mathrm{ppm}$ ) of Kdo and to the H3 and H3' $(\delta 1.88$ and $2.20 \mathrm{ppm}$ ) of Dha (Fig. 6b), which are challenging to identify by glycosyl residue composition analyses. These data also illustrate how the presence of acetyl- and methylesters complicate the NMR analysis of complex glycans. In addition, the ${ }^{1} \mathrm{H}$-NMR spectrum of the RG-II monomer both before (Fig. 6a) and after (Fig. 6b) de-esterification contained characteristic intensive signals that were assigned to base-stable methyl-ethers $(\delta 3.50$ and $3.48 \mathrm{ppm}$ ) (Fig. 6a, b). It is notable that these signals are less intense in the native and base-treated dimer spectra (Fig. 6c, d). Together, these data demonstrate the utility of 


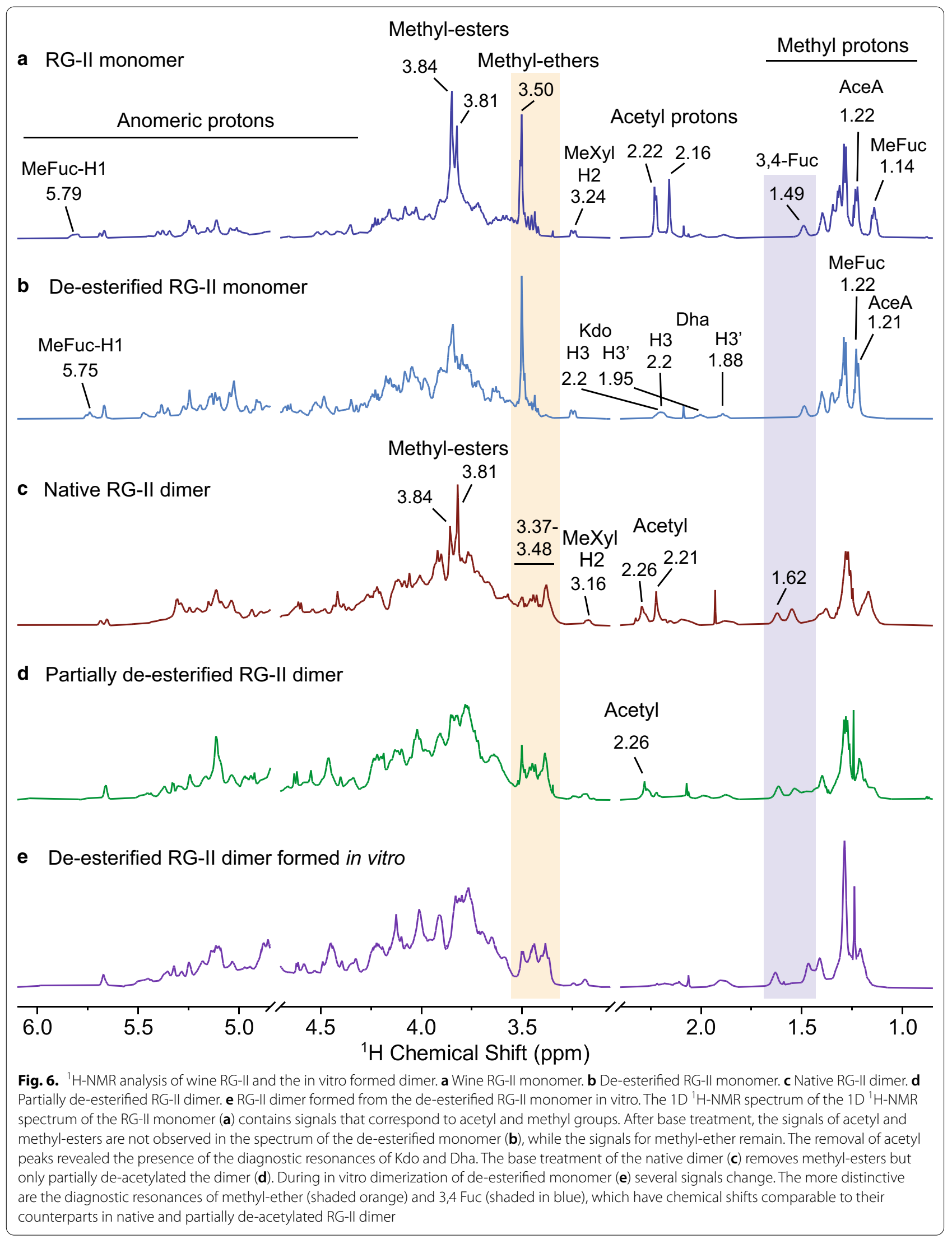


Table 3 Selected signals in the $1 \mathrm{H}-\mathrm{NMR}$ spectra of the RG-II monomer before and after base treatment

\begin{tabular}{|c|c|c|}
\hline \multirow[t]{2}{*}{ RG-II residue/group protons } & \multicolumn{2}{|c|}{${ }^{1} \mathrm{H}$ chemical shifts (ppm) } \\
\hline & RG-II monomer & $\begin{array}{l}\text { Base- } \\
\text { treated RG-II } \\
\text { monomer }\end{array}$ \\
\hline Methyl-ester protons & $3.81,3.84$ & nd \\
\hline Acetyl protons & $2.16,2.22$ & nd \\
\hline 2Me-a-L-Fucp-(1 $\rightarrow 2 \mathrm{H} 6$ & 1.14 & 1.22 \\
\hline$\rightarrow 2)$-a-L-AcefA- $(1 \rightarrow 3 \mathrm{H} 5$ & 1.22 & 1.21 \\
\hline 2Me-a-L-Fucp-(1 $\rightarrow 2 \mathrm{H} 1$ & 5.79 & 5.75 \\
\hline $\begin{array}{l}-5)-\mathrm{a}-\mathrm{D}-\mathrm{Kdo}-(2 \rightarrow 3 \\
\mathrm{H} 3, \mathrm{H}^{\prime}\end{array}$ & 1.88, nd & $1.88,2.2$ \\
\hline $\begin{array}{l}-5)-\beta-D-D h a-(2 \rightarrow 3 \\
\text { H3, H3' }\end{array}$ & 1.95, nd & $1.95,2.2$ \\
\hline
\end{tabular}

$N d$ not determined

using NMR as a complementary approach to MS-based methods for the characterization of complex pectins.

\section{Studying RG-Il dimerization in vitro using SEC and NMR spectroscopy}

The methods discussed thus far provide the necessary tools to isolate RG-II and characterize its glycosyl and non-glycosyl components. When elucidating the role of RG-II in plants, we must consider not only its structure but the function of the molecule as it pertains to its cross-linking by borate (Fig. 1b). To study factors that affect RG-II dimerization, we first generate the RG-II monomer by treating the dimer $(2.5 \mathrm{mg} /$ $\mathrm{mL}$ ) for $1 \mathrm{~h}$ at room temperature with $0.1 \mathrm{M} \mathrm{HCl}$ (Additional file 1: Fig. S5a). These conditions hydrolyze the borate diester but have no discernible effect on glycosidic linkages or non-glycosyl modifications. The acid is removed by dialysis against deionized water and the resulting monomer is freeze-dried. At this point, a stock solution of RG-II monomer in water $(5 \mathrm{mg} / \mathrm{mL})$ can be prepared and stored frozen. It is important to use known amounts of monomer since the rate and extent of dimer formation in vitro is sensitive to the concentrations of the monomer, boric acid, and divalent cation [33]. Our standard reaction mixture consists of RG-II monomer $(50 \mu \mathrm{g})$ in $50 \mathrm{mM} \mathrm{NaOAc} \mathrm{pH} 3.6$ (50 $\mu \mathrm{L}$ ) containing $1 \mathrm{mM}$ boric acid and $0.5 \mathrm{mM} \mathrm{Pb}\left(\mathrm{NO}_{3}\right)_{2}$. The reaction is allowed to proceed at room temperature for at least $15 \mathrm{~min}$ and the products formed can be analyzed by SEC on a Superdex 75 column coupled with RI detection. We routinely use this procedure to determine the effects of $\mathrm{pH}$, temperature, and cations on the rate of dimer formation [12]. For example, the presence of lead cations substantially increases the rate of dimer formation in vitro, whereas in the absence of lead the dimerization process may require at least $16 \mathrm{~h}$ to achieve significant conversion (Additional file 1: Fig. $\mathrm{S} 5 \mathrm{~b}, \mathrm{c})$ [33]. $\mathrm{Pb}\left(\mathrm{NO}_{3}\right)_{2}$ at concentrations above $1 \mathrm{mM}$ is not soluble in some of the buffers used to investigate dimer formation, but can be replaced with an equivalent or higher concentration of $\mathrm{SrCl}_{2}$ or $\mathrm{BaCl}_{2}$. However, the $\mathrm{Sr}^{2+}$ and $\mathrm{Ba}^{2+}$ cations are not as effective at promoting dimerization as $\mathrm{Pb}^{2+}[49]$. Somewhat surprisingly, we have found that adding $\mathrm{Ca}^{2+}$ does not increase the rate of dimer formation in vitro [35].

We also use ${ }^{1} \mathrm{H}$-NMR spectroscopy to study RG-II dimerization as it provides insight into the glycosyl residues that may have a role in the assembly process. For this procedure, wine RG-II dimer was converted to the monomer and then de-esterified. As mentioned above, de-esterification simplifies the NMR spectra, facilitating analysis of the dimerization process. The de-esterified monomer was then converted to the dimer by reaction with boric acid in the presence of $\mathrm{Pb}\left(\mathrm{NO}_{3}\right)_{2}$ in $\mathrm{K}$ phthalate, $\mathrm{pH} 4.0$ (Fig. 6b, e). The most notable changes are in the signals corresponding to methyl-ethers present in the monomer $(\delta 3.5 \mathrm{ppm}$; Fig. $6 \mathrm{~b})$, which broadened after in vitro formation of the dimer and are comparable to their counterparts in native and partially de-acetylated RG-II dimer (Fig. 6ce). Other signals related to methyl-ethers also change during dimerization. For example, the $\mathrm{H}-2$ signal of 2-O-MeXyl shifted upfield from 3.24 to $3.16 \mathrm{ppm}$ after in vitro dimerization, matching the chemical shift of the $\mathrm{H}-2$ of 2-O-MeXyl observed in the native RG-II dimer (Fig. 6). These results demonstrate that the chemical environment of the methyl-ether attached to xylose changes substantially during dimer formation. However, the role of this substituent in dimer formation remains to be determined. Comparison of the dimer formed in vitro with its native counterpart (Fig. 6c-e), suggests that the RG-II formed in planta and in vitro have comparable structures. It is also notable that the dimer is readily formed from the de- $O$-acetylated monomer in vitro, which indicates that the $O$-acetyl groups are not required for the reaction to occur.

${ }^{1} \mathrm{H}$-NMR spectroscopy provides little information on the existence or nature of the borate cross-link since forming a borate-diol ester has only small effects on the ${ }^{1} \mathrm{H}$-NMR spectra of a glycose including Api [70-72]. However, boron NMR ( $\left.{ }^{11} \mathrm{~B}-\mathrm{NMR}\right)$ can be used to show that borate-diol esters are present in the RG-II dimer if ${ }^{11} \mathrm{~B}$ is present. Thus, combining the results of ${ }^{1} \mathrm{H}$ - and ${ }^{11} \mathrm{~B}-\mathrm{NMR}$ spectroscopy can provide abundant information on RG-II structure and chemical composition in a non-destructive manner. 


\section{Conclusions}

Plant cell walls contain polysaccharides with a rich chemical diversity that confer specific functions relevant to plant growth and development on the cellular and organ level. However, the complexity of polysaccharides has often hindered efforts to decipher their composition and functionality. In this work, we used RG-II as a model to outline the steps necessary to isolate and characterize complex polysaccharides. We demonstrate the utility of various types of chromatographies for isolating polysaccharides based on their physicochemical characteristics, and further show how MS- and NMR-based experiments are critical for determining complex glycan structures. The protocols we have described above can be applied to the characterization of most saccharide structures and will help inform researchers on how such structures relate to the functional properties of glycans.

\section{Materials and methods}

\section{Chemicals and reagents}

All chemicals and reagents were purchased from Sigma (Sigma, USA) unless otherwise noted. Dialysis was carried out using Spectrum ${ }^{\mathrm{TM}}$ Spectra/Por $^{\mathrm{TM}}$, 3500 Dalton MWCO tubing (Spectrum Chemical Mfg Corp, USA).

\section{Plant material}

W. repanda (ID9122) was obtained from the Rutgers Duckweed Stock Cooperative (Rutgers University, New Brunswick, NJ, USA). Plants were grown on $0.8 \%(\mathrm{w} / \mathrm{v})$ agar $\mathrm{pH} 5.8$, containing Schenk and Hildebrandt basal salts $(1.6 \mathrm{~g} / \mathrm{L})$ and sucrose $(1 \% \mathrm{w} / \mathrm{v})$ in an Adaptis A1000 growth chamber (Conviron, Canada) at $19{ }^{\circ} \mathrm{C}$ and $15{ }^{\circ} \mathrm{C}$ with a $14 \mathrm{~h}$ light $-10 \mathrm{~h}$ dark cycle, respectively, and a light intensity of $120 \mu \mathrm{mol}$ quanta $\mathrm{m}^{-2} \mathrm{~s}^{-1}$. After 14 days of growth, the plants were washed from the surface of the agar using deionized water and kept at $-20{ }^{\circ} \mathrm{C}$. Celery stalks (petioles) were purchased from a local supermarket.

\section{Preparation of cell walls}

Cell walls were prepared from celery petioles and from $W$. repanda plants as their alcohol insoluble residues (AIR) as described [6]. Plant material can be harvested onto dry ice or into liquid nitrogen and kept at $-80{ }^{\circ} \mathrm{C}$ until required. For AIR preparation, plant material was suspended in aqueous $80 \%(\mathrm{v} / \mathrm{v})$ ethanol and the tissue disrupted using a Polytron $\odot$ homogenizer. The homogenate was then filtered through $100 \mu \mathrm{m}$ nylon mesh and washed extensively with aqueous $80 \%$ ethanol. The homogenized tissue was suspended in chloroform:methanol $(1: 1 \mathrm{v} / \mathrm{v})$ and stirred for a minimum of $1 \mathrm{~h}$ (or overnight) at room temperature and $125 \mathrm{rpm}$ in a fume hood. The suspension was filtered through $100 \mu \mathrm{m}$ nylon mesh, washed with chloroform:methanol, with acetone, and then air-dried. The final isolated residue is referred to as the alcohol insoluble residue (AIR). Starch was removed by treating suspensions of the AIR (in 0.5-1.0 g batches) in $50 \mathrm{mM}$ sodium acetate $(\mathrm{NaOAc}) \mathrm{pH} 5.2$, for $24 \mathrm{~h}$ at $45{ }^{\circ} \mathrm{C}$ with the glucoamylase Spirizyme ${ }^{\circledR}(60 \mu \mathrm{L} / g$; Novozymes A/S, Denmark) and the $\alpha$-amylase Liquozyme ${ }^{\circledR}$ (300 $\mu \mathrm{L} / g$; Novozymes A/S, Denmark). The de-starched AIR was collected by filtration through nylon mesh (100 $\mu \mathrm{m}$ pore size, ThermoFisher, Waltham, MA, USA) and washed with deionized water.

\section{Isolation of pectins from plant cell walls and red wine}

A pectin fraction containing RG-II was solubilized by treating $W$. repanda AIR ( $2 \mathrm{~g})$ for $16 \mathrm{~h}$ at room temperature with $50 \mathrm{mM}$ ammonium oxalate $(250 \mathrm{~mL}) \mathrm{pH} 6$ [42]. The oxalate-soluble material was dialyzed (3500 Dalton MWCO) against deionized water and freeze-dried. A solution of the oxalate-soluble material $(200 \mathrm{mg})$ in $50 \mathrm{mM} \mathrm{NaOAc} \mathrm{pH} \mathrm{5.2,} \mathrm{was} \mathrm{then} \mathrm{treated} \mathrm{for} 24 \mathrm{~h}$ at $30{ }^{\circ} \mathrm{C}$ with endopolygalacturonase M2 (EPG) from Aspergillus aculeatus (2U Megazyme, Ireland). The solution was dialyzed (3500 Dalton MWCO) against deionized water and freeze-dried.

A suspension of celery AIR (25 g) in $50 \mathrm{mM} \mathrm{NaOAc}$ (1 L) $\mathrm{pH} 5.2$, was treated for $24 \mathrm{~h}$ at $30{ }^{\circ} \mathrm{C}$ with EPG (5 $\mathrm{U} / \mathrm{g}$ ) with shaking at $150 \mathrm{rpm}$. The EPG-treated AIR was collected by filtration through nylon mesh $(100 \mu \mathrm{m}$ pore size) and retreated with EPG as before and filtered. The enzyme solubilized materials were combined, concentrated to $\sim 100 \mathrm{~mL}$ by rotary evaporation at $37{ }^{\circ} \mathrm{C}$, dialyzed (3500 Dalton MWCO) against deionized water, and freeze-dried.

Red wine (Yellow Tail Shiraz, 9 L) was concentrated to $\sim 1.5 \mathrm{~L}$ by rotary evaporation at $37{ }^{\circ} \mathrm{C}$. Absolute ethanol $(3 \mathrm{~L})$ was added and the mixture was kept overnight at $4{ }^{\circ} \mathrm{C}$. The precipitate that formed was collected by centrifugation, dissolved in water, and re-precipitated by addition of ethanol to $75 \%(\mathrm{v} / \mathrm{v})$. The second precipitate was dissolved in water, dialyzed (3500 Dalton MWCO), and freeze-dried (yield $\sim 17.5 \mathrm{~g}$ ).

\section{Purification of RG-II}

Material enriched in RG-II was obtained by SEC of the EPG-treated oxalate-soluble material from $W$. repanda AIR, the EPG-soluble material from celery AIR, and the RG-II-containing precipitate obtained from red wine.

Briefly, solutions $(500 \mu \mathrm{L})$ of the EPG-treated oxalatesoluble fraction $(10 \mathrm{mg})$ from $W$. repanda in $50 \mathrm{mM}$ ammonium formate $\mathrm{pH} 5$ were filtered using nylon $0.45 \mu \mathrm{m}$ Costar $^{\circledR}$ Spin- $\mathrm{X}^{\circledR}$ centrifuge tube filters (Corning, 
USA). SEC was carried out using a Superdex 75 Increase column (Cytiva, Marlborough, MA, USA) at $0.5 \mathrm{~mL} / \mathrm{min}$ with $50 \mathrm{mM}$ ammonium formate $\mathrm{pH} 5$, using a Dionex UltiMate 3000 pump (Thermo Scientific, USA). The column eluent was monitored with a Shodex RI-101 refractive index detector (Showa Denko America, USA). Fractions containing RG-II were collected manually and repeatedly freeze-dried to remove the ammonium formate.

A solution $(10-12 \mathrm{~mL})$ of the EPG-soluble material (200-300 mg) from celery in $50 \mathrm{mM} \mathrm{NaOAc} \mathrm{pH} 5$ was filtered as described above then fractionated by preparative SEC on a column $(1 \mathrm{~m} \times 4 \mathrm{~cm})$ of Sephadex G-75 fine (Cytiva, USA) by elution with $50 \mathrm{mM} \mathrm{NaOAc} \mathrm{pH} 5$ at $1 \mathrm{~mL} / \mathrm{min}$. Fractions $(12 \mathrm{~mL})$ were collected. Aliquots $(100 \mu \mathrm{L})$ of each fraction were assayed colorimetrically for uronic acids using the metabiphenyl assay [47] (see Fig. 2). Fractions enriched in RG-I, RG-II, and OGAs were separately pooled, dialyzed (3500 Dalton MWCO) against deionized water, and freeze-dried. Please see Additional file 1: Methods for protocols relevant to the purification of galactan from the RG-II-enriched SEC fraction from celery (Additional file 1: Materials and Methods).

The precipitate from red wine $(\sim 500 \mathrm{mg})$ was dissolved in $50 \mathrm{mM} \mathrm{NaOAc} \mathrm{pH} 5(10-12 \mathrm{~mL})$, filtered through a 0.45 um nylon filter, and then fractionated using the preparative Sephadex G-75 SEC column by elution with $50 \mathrm{mM}$ $\mathrm{NaOAc}$ pH 5 at $1 \mathrm{~mL} / \mathrm{min}$. Fractions $(12 \mathrm{~mL})$ were collected. Aliquots $(100 \mu \mathrm{L})$ of each fraction were assayed colorimetrically for uronic acids using the metabiphenyl assay (Fig. 2) [47]. Fractions enriched in AGP/RG-I, RG-II, and OGAs were separately pooled, dialyzed (3500 Dalton MWCO) against deionized water, and freeze-dried.

\section{Preparation of RG-II monomer}

The RG-II dimer was treated for $1 \mathrm{~h}$ at room temperature with $0.1 \mathrm{M} \mathrm{HCl}$ [49]. The solution was then dialyzed (3500 Dalton MWCO) against deionized water and freeze-dried. The RG-II dimer and monomer were chemically de-esterified by treatment for $16 \mathrm{~h}$ at $4{ }^{\circ} \mathrm{C}$ with $0.1 \mathrm{M} \mathrm{NaOH}$. The solution was neutralized with acetic acid, dialyzed (3500 Dalton MWCO) against water, and freeze-dried.

The dimer was formed for NMR spectroscopic analysis by reacting the de-esterified wine monomer $(2 \mathrm{mM})$ in $50 \mathrm{mM}$ potassium hydrogen phthalate $\mathrm{pH} 4.0(200 \mu \mathrm{l})$, for $16 \mathrm{~h}$ at $25^{\circ} \mathrm{C}$ with $2 \mathrm{mM}$ boric acid and $1.5 \mathrm{mM} \mathrm{Pb}\left(\mathrm{NO}_{3}\right)_{2}$.

\section{Determination of RG-II molecular mass using} multi-angle light scattering coupled with size-exclusion chromatography (SEC-MALS)

SEC-MALS analysis was performed using an Agilent 1260 HPLC system (Agilent, USA) and a Superdex 75
10/300 SEC column (Cytiva, USA) connected in series to an Optilab T-rEX differential refractometer (Wyatt Technology Co., USA) operating at $25^{\circ} \mathrm{C}$ and a Dawn Heleos 8 MALS detector (Wyatt Technology Co., USA) equipped with a He-Ne laser $(\lambda=660 \mathrm{~nm})$. The column was eluted at a flow rate of $0.5 \mathrm{~mL} / \mathrm{min}$ with $50 \mathrm{mM}$ ammonium formate $\mathrm{pH}$ 5. All data were acquired and processed using ASTRA 7 software (Wyatt Technology Co., USA).

Native esterified wine and celery RG-II monomer and dimer (1-2 mg) were dissolved in ultrapure water and filtered using $0.45 \mu \mathrm{m}$ nylon $\operatorname{Costar}^{\circledR}$ Spin- $\mathrm{X}^{\circledR}$ centrifuge tube filters (Corning, USA). The injection volume was 100 $\mu \mathrm{L}$ and a minimum of three injections for each polysaccharide were performed. The $d n / d c$ value for RG-II was calculated by analysis of the purified native celery monomer. Different amounts of monomer (1.0, 0.5, 0.2, and $0.1 \mathrm{mg}$ ) were injected, and the $d n / d c$ value was obtained on-line assuming $100 \%$ mass recovery for the peak of interest. The calculated $d n / d c$ value $(0.122 \pm 0.003 \mathrm{mg} /$ $\mathrm{mL}$ ) was used for all RG-II analyses.

\section{Glycosyl residue composition analyses}

Neutral glycosyl residue compositions were determined by GLC analysis of the alditol acetate derivatives after hydrolysis for $1.5 \mathrm{~h}$ at $120{ }^{\circ} \mathrm{C}$ with $2 \mathrm{M}$ trifluoroacetic acid (TFA) [53]. Neutral monosaccharides and hexuronic acids were also analyzed by high-performance anionexchange chromatography with pulsed amperometric detection (HPAEC-PAD) [42]. Briefly, RG-II (1-2 mg) was hydrolyzed for $1.5 \mathrm{~h}$ at $120{ }^{\circ} \mathrm{C}$ with $2 \mathrm{M}$ TFA (250 $\mu \mathrm{L})$. The hydrolysate was concentrated to dryness, dissolved in water $(250 \mu \mathrm{L})$ and a portion $(25 \mu \mathrm{L})$ analyzed HPAEC-PAD using a CarboPac PA1 column (Thermo Fisher, USA) using a Dionex ICS-3000 ion chromatography system (ThermoFisher, USA). The column was eluted at $1.0 \mathrm{~mL} \mathrm{~min}^{-1}$ with $32 \mathrm{mM} \mathrm{NaOH}(0-15 \mathrm{~min})$ followed by a gradient of NaOAc $(0-0.25 \mathrm{M})$ in $100 \mathrm{mM}$ $\mathrm{NaOH}(15-35 \mathrm{~min})$, a gradient of NaOAc $(0.25-1 \mathrm{M})$ in $100 \mathrm{mM} \mathrm{NaOH}$ (35-45 min), and then with $1 \mathrm{M} \mathrm{NaOAc}$ in $100 \mathrm{mM} \mathrm{NaOH}$ (45-48 min). The column was equilibrated for 12 min with $32 \mathrm{mM} \mathrm{NaOH}$ prior to the next injection.

Neutral and acidic glycosyl residue compositions, including Kdo and Dha, were identified by analysis of the trimethylsilyl methyl glycoside derivatives as described [73]. Briefly, RG-II $(250 \mu \mathrm{g})$ was suspended in methanolic $1 \mathrm{M} \mathrm{HCl}(250 \mu \mathrm{L})$ in screw-top glass tubes secured with Teflon-lined caps and heated for $18 \mathrm{~h}$ at $80^{\circ} \mathrm{C}$. After cooling to room temperature, the solutions were concentrated to dryness under a stream of nitrogen gas. The released methyl glycosides and methyl glycoside methylesters were then reacted for $30 \mathrm{~min}$ at $80{ }^{\circ} \mathrm{C}$ with Tri-Sil ${ }^{\circledR}$ 
(ThermoFisher, USA). GLC-EI-MS analysis of the TMS methyl glycosides was performed on an Agilent 7890A GC interfaced to an Agilent 5975C mass selective detector, with a Supelco Equity-1 fused silica capillary column $(30 \mathrm{~m} \times 0.25 \mathrm{~mm} \mathrm{ID})$.

\section{Generation of side chains A and B}

Solutions of RG-II $(\sim 500 \mu \mathrm{g})$ in $0.1 \mathrm{M}$ TFA $(500 \mu \mathrm{L})$ were kept for $1 \mathrm{~h}$ at $80^{\circ} \mathrm{C}$ and for $16 \mathrm{~h}$ at $40{ }^{\circ} \mathrm{C}$. The solutions were concentrated to dryness under a flow of air and the residue washed with methanol $(2 \times 1 \mathrm{~mL})$. The residues were dissolved in water $(500 \mu \mathrm{L})$ and the acidic oligosaccharides isolated using graphitized carbon [74]. Briefly, Supelclean $^{\mathrm{TM}}$ ENVI $^{\mathrm{TM}}{ }^{-}$-Carb cartridges ( $1 \mathrm{~mL}$; Sigma, USA) were conditioned by washing with $2 \mathrm{ml}$ of aqueous $80 \%$ $(\mathrm{v} / \mathrm{v})$ acetonitrile containing $0.1 \%$ TFA, followed by $5 \mathrm{ml}$ of deionized water. The hydrolysates were then applied to the cartridge and the bound material washed with $2.5 \mathrm{~mL}$ of deionized water. Acidic oligosaccharides were then eluted with $3 \mathrm{~mL}$ of aqueous $50 \%$ acetonitrile containing $0.1 \%$ TFA, which was concentrated to dryness under a flow of warm air. The residue was dissolved in water $(100-300 \mu \mathrm{L})$ and analyzed by ESI MS in the positive ion mode.

\section{Glycosyl-linkage analysis of W. repanda and celery side chain B}

Fractions enriched in RG-II side chain B from W. repanda and celery RG-II were obtained by Superdex 75 SEC of the material generated by treatment of RG-II $(\sim 3 \mathrm{mg})$ with $0.1 \mathrm{M}$ TFA $(500 \mu \mathrm{L})$ for $16 \mathrm{~h}$ at $40^{\circ} \mathrm{C}$. One half of the fraction was then treated with $\mathrm{NaBH}_{4}(10 \mathrm{mg} / \mathrm{mL} 2 \mathrm{M}$ ammonium hydroxide) to convert the oligosaccharides to their corresponding oligosaccharide-alditols. The oligosaccharides and the oligosaccharide-alditols were then separately per-O-methylated using solid $\mathrm{NaOH}$ in dimethylsulfoxide (DMSO) and methyl iodide [75]. Briefly, $200 \mu \mathrm{L}$ of aqueous $50 \% \mathrm{NaOH}$ was transferred to a screw-cap tube and then anhydrous methanol $(200 \mu \mathrm{L})$ was added. The mixture was vortexed and then mixed with DMSO $(4 \mathrm{~mL})$. The suspension was centrifuged for $2 \mathrm{~min}$ at $2000 \times g$ and the DMSO and any white precipitate that formed was then carefully removed with a glass Pasteur pipette. This treatment was repeated a further four times until the pellet of solid $\mathrm{NaOH}$ was opalescent. The $\mathrm{NaOH}$ pellet was then suspended in DMSO $(1.5 \mathrm{~mL})$ and a portion $(200 \mu \mathrm{L})$ was added to solutions of the oligosaccharide in DMSO $(200 \mu \mathrm{L})$. The mixture was kept for $15 \mathrm{~min}$ at room temperature and then methyl iodide $(100 \mu \mathrm{L})$ was added dropwise. After $30 \mathrm{~min}$, water $(1.5 \mathrm{~mL})$ was added and the excess methyl iodide was then removed by gently bubbling nitrogen gas through the liquid. The methylated products were extracted into dichloromethane and portions analyzed by ESI-MS. The remaining material was converted to partially methylated alditol acetate derivatives and analyzed by GLC-EI-MS [53].

\section{Nanospray electrospray ionization mass spectrometry (ESI-MS)}

Solutions of the native or per-O-methylated oligosaccharides $(\sim 1 \mathrm{mg} / \mathrm{mL})$ were diluted tenfold with aqueous $50 \%$ methanol containing $0.1 \% \mathrm{v} / \mathrm{v}$ formic acid and directly infused at $0.5 \mu \mathrm{L} / \mathrm{min}$ into the nanospray ionization source of an Orbitrap Fusion Tribrid mass spectrometer (Thermo Fisher Scientific, USA) operated in the positive mode with an applied voltage of $1.9 \mathrm{kV}$. An automated program was used to collect a full mass spectrum and the $\mathrm{MS}^{2}$ of the highest intensity peaks. The top 300 peaks collected over an $\mathrm{m} / \mathrm{z}$ range of 400-2000 were fragmented by collision-induced dissociation, with a dynamic exclusion of $60 \mathrm{~s}$. The total run time was $20 \mathrm{~min}$. Full mass spectra were collected at a resolution of 120,000 while the $\mathrm{MS}^{2}$ spectra were collected at a resolution of 60,000 [76]. Spectra were interpreted manually and with GlycoWorkbench 2 software.

\section{${ }^{1} \mathrm{H}$-NMR spectroscopy}

${ }^{1} \mathrm{H}-\mathrm{NMR}$ spectra were recorded with a Varian NMR spectrometer (Agilent Technologies) operating at $600 \mathrm{MHz}$ using a $5 \mathrm{~mm}$ cold probe. RG-II samples were dissolved in $\mathrm{D}_{2} \mathrm{O}(0.2 \mathrm{~mL}, 99.9 \%$; Cambridge Isotope Laboratories, Tewksbury, MA, USA) and placed in a $3 \mathrm{~mm}$ NMR tube. ${ }^{1} \mathrm{H}$-NMR spectra were obtained using standard Varian pulse programs. Chemical shifts were measured relative to internal DMSO $(\delta H$ 2.721) or acetone $(\delta H 2.225)$. Data were processed using MestReNova software (Mestrelab Research S.L., Spain).

\section{Abbreviations}

AIR: Alcohol insoluble residue; Araf: Arabinofuranose; Arap: Arabinopyranose; AceA: Aceric acid, 3-C-carboxy-5-deoxy-L-xylose; AGA: Apiogalacturonan; AGP: Arabinogalactan protein; APAP1: Arabinoxylan pectin arabinogalactan protein 1; Api: Apiose; ${ }^{11} \mathrm{~B}-\mathrm{NMR}$ : Boron nuclear magnetic resonance spectroscopy; CDTA: 1,2-Cyclohexylenedinitrilotetraacetic acid; Dha: 3-Deoxy-Dlyxo-2-heptulopyranosylaric acid; DHB: 2,5-Dihydroxybenzoic acid; DMSO: Dimethylsulfoxide; $d n / d c$ : Specific refractive index increment; $\mathrm{D}_{2} \mathrm{O}$ : Dueterium oxide; EDTA: Ethylenediaminetetraacetic acid; EPG: Endopolygalacturonase; 2MeFuc: 2-O-Me-L-Fucose; 2MeXyl: 2-O-Methyl xylose; ESI-MS: Electrospray ionization mass spectrometry; Gal: Galactose; GalA: Galacturonic acid;

GLC-EI-MS: Gas liquid chromatography with electron impact mass spectrometry; ${ }^{1} H-N M R$ : Proton nuclear magnetic resonance spectroscopy; HPAEC-PAD: High-performance anion-exchange chromatography with pulsed amperometric detection; Kdo: 2-Keto-3-deoxy-manno-octulosonic acid; MALDI-TOFMS: Matrix-assisted laser-desorption time-of-flight mass spectrometry; MALS: Multi-angle laser light scattering; MWCO: Molecular weight cutoff; MS: Mass spectrometry; $\mathrm{NaBD}_{4}$ : Sodium borodueteride; NaOAc: Sodium acetate; NMR: Nuclear magnetic resonance spectroscopy; OGAs: Oligogalacturonides; RG-I: Rhamnogalacturonan I; RG-II: Rhamnogalacturonan-II; Rha: Rhamnose; RI: Refractive index; SEC: Size-exclusion chromatography; SEC-MALS: Size-exclusion chromatography with multi-angle laser light scattering; TFA: Trifluoroacetic acid; XGA: Xylogalacturonan. 


\section{Supplementary Information}

The online version contains supplementary material available at https://doi. org/10.1186/s13068-021-01992-0.

Additional file 1. Supplemental Materials and Methods, Supplemental Table S1, and Supplemental Figures S1 - S5.

\section{Acknowledgements}

We thank Yuval Shoham of the Technion-Israel Institute of Technology, Haifa, Israel for the gift of the Geobacillus stearothermophilus GanA plasmid and Pradeep Prabhakar of the CCRC for producing the G. stearothermophilus galactanase

\section{Authors' contributions}

All the authors read and approved the final manuscript.

\section{Funding}

The work performed by WJB, SK, MJP, BU, and MAO was supported by the Division of Chemical Sciences, Geosciences, and Biosciences, Office of Basic Energy Sciences of the United States Department of Energy through Grant DESC0008472 for funding structural studies of RG-II. The work performed by SAA-H, IMB, and PA was supported in part by National Institutes of Health (NIH)-funded Research Resource for Biomedical Glycomics (1S100D018530) and the Chemical Sciences, Geosciences and Biosciences Division, Office of Basic Energy Sciences, U.S. Department of Energy Grant (DESC0015662) at the Complex Carbohydrate Research Center.

\section{Availability of data and materials}

The datasets generated during the current study are available from the corresponding author on reasonable request.

\section{Declarations}

Ethics approval and consent to participate

Not applicable.

\section{Consent for publication}

Not applicable.

\section{Competing interests}

The authors declare that they have no competing interests.

\section{Author details}

${ }^{1}$ Complex Carbohydrate Research Center, The University of Georgia, 315 Riverbend Road, Athens, GA 30602, USA. ${ }^{2}$ The Department of Biochemistry and Molecular Biology, The University of Georgia, Athens, GA 30602, USA.

\section{Received: 5 February 2021 Accepted: 10 June 2021}

Published online: 22 June 2021

\section{References}

1. Cosgrove DJ. Re-constructing out models of cellulose and primary cell wall assembly. Curr Opin Plant Biol. 2014;22:122-31.

2. Park YB, Cosgrove DJ. A revised architecture of primary cell walls based on biomechanical changes induced by substrate-specific endoglucanases. Plant Physiol. 2012;158:1933-43.

3. Park YB, Cosgrove DJ. Changes in cell wall biomechanical properties in the xyloglucan-deficient xxt1/xxt2 mutant of Arabidopsis. Plant Physiol. 2012;158:465-75.

4. Simmons TJ, Mortimer JC, Bernardinelli OD, Poppler AC, Brown SP, deAzevedo ER, Dupree R, Dupree P. Folding of xylan onto cellulose fibrils in plant cell walls revealed by solid-state NMR. Nat Commun. 2016:7:13902

5. Willats WG, McCartney L, Mackie W, Knox JP. Pectin: cell biology and prospects for functional analysis. Plant Mol Biol. 2001;47:9-27.
6. Muszyński A, O’Neill MA, Ramasamy E, Pattathil S, Avci U, Peña MJ, Libault M, Hossain MS, Brechenmacher L, York WS, Barbosa RM, Hahn MG, Stacey G, Carlson RW. Xyloglucan, galactomannan, glucuronoxylan, and rhamnogalacturonan I do not have identical structures in soybean root and root hair cell walls. Planta. 2015:242:1123-38.

7. Wang T, Hong M. Solid-state NMR investigations of cellulose structure and interactions with matrix polysaccharides in plant primary cell walls. J Exp Bot. 2016;67:503-14.

8. Wang $X$, Wilson L, Cosgrove DJ. Pectin methylesterase selectively softens the onion epidermal wall yet reduces acid-induced creep. J Exp Bot. 2020;71:2629-40

9. Xiao C, Barnes WJ, Zamil MS, Yi H, Puri VM, Anderson CT. Activation tagging of Arabidopsis POLYGALACTURONASE INVOLVED IN EXPANSION2 promotes hypocotyl elongation, leaf expansion, stem lignification, mechanical stiffening, and lodging. Plant J. 2017;89:1159-73.

10. Rui Y, Xiao C, Yi H, Kandemir B, Wang JZ, Puri VM, Anderson CT. Polygalacturonase involved in expansion3 functions in seedling development, rosette growth, and stomatal dynamics in Arabidopsis thaliana. Plant Cell. 2017;29:2413-32

11. Atkinson RG, Schroder R, Hallett IC, Cohen D, MacRae EA. Overexpression of polygalacturonase in transgenic apple trees leads to a range of novel phenotypes involving changes in cell adhesion. Plant Physiol. 2002;129:122-33.

12. Francis KE, Lam SY, Copenhaver GP. Separation of Arabidopsis pollen tetrads is regulated by QUARTET1, a pectin methylesterase gene. Plant Physiol. 2006;142:1004-13.

13. Rhee SY, Osborne E, Poindexter PD, Somerville CR. Microspore separation in the quartet 3 mutants of Arabidopsis is impaired by a defect in a developmentally regulated polygalacturonase required for pollen mother cell wall degradation. Plant Physiol. 2003;133:1170-80.

14. Usadel B, Kuschinsky AM, Rosso MG, Eckermann N, Pauly M. RHM2 is involved in mucilage pectin synthesis and is required for the development of the seed coat in Arabidopsis. Plant Physiol. 2004;134:286-95.

15. Voiniciuc C, Engle KA, Gunl M, Dieluweit S, Schmidt MH, Yang JY, Moremen KW, Mohnen D, Usadel B. Identification of key enzymes for pectin synthesis in seed mucilage. Plant Physiol. 2018;178:1045-64.

16. Iwai H, Masaoka N, Ishii T, Satoh S. A pectin glucuronyltransferase gene is essential for intercellular attachment in the plant meristem. Proc Natl Acad Sci USA. 2002;99:16319-24.

17. Krupkova $\mathrm{E}$, Immerzeel P, Pauly M, Schmulling T. The TUMOROUS SHOOT DEVELOPMENT2 gene of Arabidopsis encoding a putative methyltransferase is required for cell adhesion and co-ordinated plant development. Plant J. 2007;50:735-50

18. Mouille G, Ralet MC, Cavelier C, Eland C, Effroy D, Hematy K, McCartney L, Truong HN, Gaudon V, Thibault JF, Marchant A, Hofte H. Homogalacturonan synthesis in Arabidopsis thaliana requires a Golgi-localized protein with a putative methyltransferase domain. Plant J. 2007:50:605-14.

19. Bou Daher F, Chen Y, Bozorg B, Clough J, Jönsson H, Braybrook SA. Anisotropic growth is achieved through the additive mechanical effect of material anisotropy and elastic asymmetry. Elife. 2018;7:e38161.

20. Verger S, Long Y, Boudaoud A, Hamant O. A tension-adhesion feedback loop in plant epidermis. eLife. 2018;7:e34460.

21. da Silva JA, Rao MA. Pectins: structure, functionality, and uses. In: Stephen AM, Phillips GO, Williams PA, editors. Food polysaccharides and their applications. Boca Raton:Taylor and Francis ; 2006; pp 353-412

22. Biswal AK, Atmodjo MA, Li M, Baxter HL, Yoo CG, Pu Y, Lee Y-C, Mazarei M, Black IM, Zhang J-Y, Ramanna H, Bray AL, King ZR, LaFayette PR, Pattathil S, Donohue BS, Mohanty SS, Ryno D, Yee K, Thompson OA, Rodrigues M, Dumitrache A, Natzke J, Winkeler K, Collins C, Yang X, Tan L, Sykes RW, Gjersing EJ, Ziebell A, Turner GB, Decker SR, Hahn MG, Davison BH, Udvardi MK, Mielenz JR, Davis MF, Nelson RS, Parrott WA, Ragauskas AJ, Neal Stewart C, Mohnen D. Sugar release and growth of biofuel crops are improved by downregulation of pectin biosynthesis. Nat Biotechnol. 2018;36:249-57.

23. Li M, Yoo CG, Pu Y, Biswal AK, Tolbert AK, Mohnen D, Ragauskas AJ. Downregulation of pectin biosynthesis gene GAUT4 leads to reduced ferulate and lignin-carbohydrate cross-linking in switchgrass. Commun Biol. 2019:2:1-11.

24. Harding SA, Tsai C-J Cell wall pectins in tree growth and woody biomass utilization. Adv Bot Res. 2019;89:235-56. 
25. Pérez Espitia PJ, Du W-X, de Jesús Avena-Bustillos R, de Fátima Ferreira Soares N, McHugh TH. Edible films from pectin: physical-mechanical and antimicrobial properties - a review. Food Hydrocolloids. 2014;35:287-96.

26. Thakur BR, Singh RK, Handa AK, Rao MA. Chemistry and uses of pectin-a review. Crit Rev Food Sci Nutr. 1997;37:47-73.

27. Thakur S, Chaudhary J, Kumar V, Thakur VK. Progress in pectin based hydrogels for water purification: trends and challenges. J Environ Manage. 2019;238:210-23.

28. Tan L, Eberhard S, Pattathil S, Warder C, Glushka J, Yuan C, Hao Z, Zhu X, Avci U, Miller JS, Baldwin D, Pham C, Orlando R, Darvill A, Hahn MG, Kieliszewski MJ, Mohnen D. An Arabidopsis cell wall proteoglycan consists of pectin and arabinoxylan covalently linked to an arabinogalactan protein. Plant Cell. 2013;25:270-87.

29. Atmodjo MA, Hao Z, Mohnen D. Evolving views of pectin biosynthesis. Annu Rev Plant Biol. 2013;64:747-79.

30. Vincken J-P, Schools HA, Oomen RJFJ, McCann MC, Ulvskov P, Voragen AGJ, Visser RGF. If homogalacturonan were a side chain of rhamnogalacturonan I. Implications for cell wall architecture. Plant Physiol. 2003;132:1781-9.

31. Perrone $P$, Hewage $C M$, Thomson AR, Bailey K, Sadler IH, Fry SC. Patterns of methyl and O-acetyl esterification in spinach pectins: new complexity. Phytochemistry. 2002;60:67-77.

32. O'Neill MA, Ishii T, Albersheim P, Darvill AG. Rhamnogalacturonan II: structure and function of a borate cross-linked cell wall pectic polysaccharide. Annu Rev Plant Biol. 2004;55:109-39.

33. O'Neill M, Black IM, Urbanowicz BR, Bharadwaj V, Crowley M, Koj S, Peña MJ. Locating methyl-etherified and methyl-esterified uronic acids in the plant cell wall pectic polysaccharide Rhamnogalacturonan II. SLAS Technol. 2020;25:329-44.

34. Ndeh D, Rogowski A, Cartmell A, Luis AS, Basle A, Gray J, Venditto I, Briggs J, Zhang X, Labourel A, Terrapon N, Buffetto F, Nepogodiev S, Xiao Y, Field RA, ZhuY, O'Neill MA, Urbanowicz BR, York WS, Davies GJ, Abbott DW, Ralet MC, Martens EC, Henrissat B, Gilbert HJ. Complex pectin metabolism by gut bacteria reveals novel catalytic functions. Nature. 2017:544:65-70.

35. Ishii T, Matsunaga T, Pellerin P, O'Neill MA, Darvill A, Albersheim P. The plant cell wall polysaccharide rhamnogalacturonan II self-assembles into a covalently cross-linked dimer. J Biol Chem. 1999;274:13098-104.

36. O'Neill MA, Eberhard S, Albersheim P, Darvill AG. Requirement of borate cross-linking of cell wall rhamnogalacturonan II for Arabidopsis growth. Science. 2001;294:846-9.

37. Ahn JW, Verma R, Kim M, Lee JY, Kim YK, Bang JW, Reiter WD, Pai HS. Depletion of UDP-D-apiose/UDP-D-xylose synthases results in rhamnogalacturonan-II deficiency, cell wall thickening, and cell death in higher plants. J Biol Chem. 2006;281:13708-16.

38. Delmas F, Seveno M, Northey JG, Hernould M, Lerouge P, McCourt P, Chevalier $C$. The synthesis of the rhamnogalacturonan II component 3-deoxy-D-manno-2-octulosonic acid (Kdo) is required for pollen tube growth and elongation. J Exp Bot. 2008;59:2639-47.

39. Voxeur A, Gilbert L, Rihouey C, Driouich A, Rothan C, Baldet P, Lerouge P. Silencing of the GDP-D-mannose 3,5-epimerase affects the structure and cross-linking of the pectic polysaccharide rhamnogalacturonan II and plant growth in tomato. J Biol Chem. 2011;286:8014-20.

40. Panter PE, Kent O, Dale M, Smith SJ, Skipsey M, Thorlby G, Cummins I, Ramsay N, Begum RA, Sanhueza D, Fry SC, Knight MR, Knight H. MUR1mediated cell-wall fucosylation is required for freezing tolerance in Arabidopsis thaliana. New Phytol. 2019;224:1518-31.

41. Zhao X, Ebert B, Zhang B, Liu H, Zhang Y, Zeng W, Rautengarten C, Li $H$, Chen X, Bacic A, Wang G, Men S, Zhou Y, Heazlewood JL, Wu A-M UDP-Api/UDP-Xyl synthases affect plant development by controlling the content of UDP-Api to regulate the RG-II-borate complex. Plant J. 2020;104:252-67.

42. Avci U, Peña M, O'Neill MA. Changes in the abundance of cell wall apiogalacturonan and xylogalacturonan and conservation of rhamnogalacturonan II structure during the diversification of the Lemnoideae. Planta. 2018:247:953-71.

43. Mort A, Moerschbacher B, Pierce M, Maness N. Problems encountered during the extraction, purification, and chromatography of pectic fragments, and some solutions to them. Carbohyd Res. 1991;215:219-27.

44. Darvill AG, McNeil M, Albersheim P. Structure of plant cell walls: VIII a new pectic polysaccharide. Plant Physiol. 1978;62:418-27.
45. Pellerin P, Doco T, Vidal S, Williams P, Brillouet JM, O'Neill MA. Structural Characterization of red wine rhamnogalacturonan II. Carbohydr Res. 1996;290:183-97.

46. Vidal S, Williams P, Doco T, Moutounet M, Pellerin P. The polysaccharides of red wine: total fractionation and characterization. Carbohydr Polym. 2003;54:439-47.

47. Blumenkrantz N, Asboe-Hansen G. New method for quantitative determination of uronic acids. Anal Biochem. 1973;54:484-9.

48. Ishii T, Thomas J, Darvill A, Albersheim P. Structure of plant cell walls: XXVI. The walls of suspension-cultured sycamore cells contain a family of rhamnogalacturonan---like pectic polysaccharides. Plant Physiol. 1989;89:421-8.

49. O'Neill MA, Warrenfeltz D, Kates K, Pellerin P, Doco T, Darvill AG, Albersheim P. Rhamnogalacturonan-II, a pectic polysaccharide in the walls of growing plant cell, forms a dimer that is covalently cross-linked by a borate ester. In vitro conditions for the formation and hydrolysis of the dimer. J Biol Chem. 1996;271:22923-30.

50. Cheong K-L, Wu D-T, Zhao J, Li S-P. A rapid and accurate method for the quantitative estimation of natural polysaccharides and their fractions using high performance size exclusion chromatography coupled with multi-angle laser light scattering and refractive index detector. J Chromatogr A. 2015;1400:98-106.

51. York WS, Darvill AG, McNeil M, Albersheim P. 3-Deoxy-D-manno2-octulosonic acid (KDO) is a component of rhamnogalacturonan II, a pectic polysaccharide in the primary cell walls of plants. Carbohydr Res. 1985;138:109-26.

52. Stevenson TT, Darvill AG, Albersheim P. Structural features of the plant cell-wall polysaccharide rhamnogalacturonan-II. Carbohydr Res. 1988;182:207-26

53. York WS, Darvill AG, MCNeil M, Stevenson TT, Albersheim P. Isolation and characterization of plant cell walls and cell wall components. Methods Enzymol. 1986;118:3-40.

54. Stevenson TT, Darvill AG, Albersheim P. 3-Deoxy-D-lyxo-2-heptulosaric acid, a component of the plant cell-wall polysaccharide rhamnogalacturonan-II. Carbohydr Res. 1988;179:269-88.

55. Jones TM, Albersheim P. A gas chromatographic method for the determination of aldose and uronic acid constituents of plant cell wall polysaccharides. Plant Physiol. 1972;49:926-36.

56. Doco T, O'Neill M, Pellerin P. Determination of the neutral and acidic glycosyl-residue compositions of plant polysaccharides by GC-El-MS analysis of the trimethylsilyl methyl glycoside derivatives. Carbohyd Polym. 2001;46:249-59.

57. Selvendran RR, March JF, Ring SG. Determination of aldoses and uronic acid content of vegetable fiber. Anal Biochem. 1979;96:282-92.

58. Azadi P, O'Neill MA, Bergmann C, Darvill AG, Albersheim P. The backbone of the pectic polysaccharide rhamnogalacturonan I is cleaved by an endohydrolase and an endolyase. Glycobiology. 1995;5:783-9.

59. Hart DA, Kindel PK. Isolation and partial characterization of apiogalacturonans from the cell wall of Lemna minor. Biochemical Journal. 1970;116:569-79.

60. Séveno M, Voxeur A, Rihouey C, Wu AM, Ishii T, Chevalier C, Ralet MC, Driouich A, Marchant A, Lerouge P. Structural characterisation of the pectic polysaccharide rhamnogalacturonan II using an acidic fingerprinting methodology. Planta. 2009;230:947-57.

61. Pabst M, Fischl RM, Brecker L, Morelle W, Fauland A, Köfeler H, Altmann F, Léonard R. Rhamnogalacturonan II structure shows variation in the side chains monosaccharide composition and methylation status within and across different plant species. Plant J. 2013;76:61-72.

62. Buffetto F, Ropartz D, Zhang XJ, Gilbert HJ, Guillon F, Ralet MC. Recovery and fine structure variability of RGIl sub-domains in wine (Vitis vinifera Merlot). Ann Bot. 2014;114:1327-37.

63. Wu D, Cui L, Yang G, Ning X, Sun L, Zhou Y. Preparing rhamnogalacturonan II domains from seven plant pectins using Penicillium oxalicum degradation and their structural comparison. Carbohydr Polym. 2018;180:209-15

64. Spellman MW, McNeil M, Darvill AG, Albersheim P, Dell A. Characterization of a structurally complex heptasaccharide isolated from the pectic polysaccharide rhamnogalacturonan II. Carbohydr Res. 1983;122:131-53.

65. Glushka JN, Terrell M, York WS, O’Neill MA, Gucwa A, Darvill AG, Albersheim P, Prestegard JH. Primary structure of the 
2-O-methyl-a-L-fucose-containing side chain of the pectic polysaccharide, rhamnogalacturonan II. Carbohydr Res. 2003:338:341-52.

66. Kailemia MJ, Ruhaak LR, Lebrilla CB, Amster IJ. Oligosaccharide analysis by mass spectrometry: a review of recent developments. Anal Chem. 2014;86:196-212.

67. Reuhs BL, Glenn J, Stephens SB, Kim JS, Christie DB, Glushka JG, Zablackis E, Albersheim P, Darvill AG, O'Neill MA. L-Galactose replaces L-fucose in the pectic polysaccharide rhamnogalacturonan II synthesized by the L-fucose-deficient mur1 Arabidopsis mutant. Planta. 2004:219:147-57.

68. Urbanowicz BR, Peña MJ, Moniz HA, Moremen KW, York WS. Two Arabidopsis proteins synthesize acetylated xylan in vitro. Plant J. 2014;80:197-206.

69. Whitcombe AJ, O'Neill MA, Steffan W, Albersheim P, Darvill AG. Structural characterization of the pectic polysaccharide, rhamnogalacturonan-II. Carbohydr Res. 1995;271:15-29.

70. Ishii T, Ono H. NMR spectroscopic analysis of the borate diol esters of methyl apiofuranosides. Carbohyd Res. 1999;321:257-60.

71. Kobayashi M, Ohno K, Matoh T. Boron nutrition of cultured tobacco BY-2 cells. II. Characterization of the boron-polysaccharide complex. Plant Cell Physiol. 1997;38:676-83.
72. Matoh T, Ishigaki K-I, Ohno K, Azuma J-I. Isolation and characterization of a boron-polysaccharide complex from radish roots. Plant Cell Physiol. 1993:34:639-42.

73. Santander J, Martin T, Loh A, Pohlenz C, Gatlin DM, Curtiss R. Mechanisms of intrinsic resistance to antimicrobial peptides of Edwardsiella ictaluri and its influence on fish gut inflammation and virulence. Microbiology (Reading). 2013;159:1471-86.

74. Packer NH, Lawson MA, Jardine DR, Redmond JW. A general approach to desalting oligosaccharides released from glycoproteins. Glycoconjugate J. 1998;15:737-47.

75. Ciucanu I, Kerek F. A simple and rapid method for the permethylation of carbohydrates. Carbohyd Res. 1984;131:209-17.

76. Shajahan A, Heiss C, Ishihara M, Azadi P. Glycomic and glycoproteomic analysis of glycoproteins - a tutorial. Anal Bioanal Chem. 2017:409:4483-505.

\section{Publisher's Note}

Springer Nature remains neutral with regard to jurisdictional claims in published maps and institutional affiliations.
Ready to submit your research? Choose BMC and benefit from:

- fast, convenient online submission

- thorough peer review by experienced researchers in your field

- rapid publication on acceptance

- support for research data, including large and complex data types

- gold Open Access which fosters wider collaboration and increased citations

- maximum visibility for your research: over 100M website views per year

At BMC, research is always in progress.

Learn more biomedcentral.com/submissions 